\title{
Pesticide Assessment Using Passive Samplers in Two River System of Cagayan De Oro River Basin, Philippines
}

Maria Luisa Baiño Salingay ( $\sim$ M.L.Salingay@tudelft.nl)

Delft University of Technology: Technische Universiteit Delft https://orcid.org/0000-0002-1822-4876

Daniel Giesen

Delft Hydraulics: Deltares

Chris Zevenbergen

TU Delft: Technische Universiteit Delft

\section{Research}

Keywords: Cagayan de Oro River Basin, GC-MS MS, LC-MS MS, passive samplers, pesticides

Posted Date: October 29th, 2020

DOl: https://doi.org/10.21203/rs.3.rs-98094/v1

License: (c) (1) This work is licensed under a Creative Commons Attribution 4.0 International License.

Read Full License 


\title{
Pesticide assessment using passive samplers in two river systems of Cagayan de Oro
}

\author{
River Basin, Philippines
}

Maria Luisa Baiño Salingay ${ }^{a, b, d}$, Daniel Giesen ${ }^{c}$, Chris Zevenbergen $^{\mathrm{a}, \mathrm{b}}$

aCivil Engineering and Geosciences, Technische Universiteit Delft (TU Delft), Building 23, Stevinweg1, 2628 CN Delft, The Netherlands

${ }_{b}$ Water Science and Engineering Department, IHE-Delft, Institute for Water Education, Westvest 72611 AX, Delft, The Netherlands

¿Deltares, Subsurface and groundwater quality, Postbus 85467, 3508 AL Utrecht, The Netherlands.

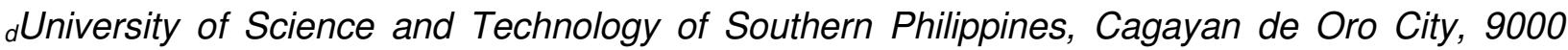
Philippines

Corresponding author: Maria Luisa Baiño Salingay

Emails: M.L.Salingay@tudelft.nl ; m.salingay@un-ihe.org ORCID Number: 0000-0002-1822-4876

\begin{abstract}
Monitoring organic pesticides in surface water using grab water sampling method is ineffective in most cases due to pesticides' irregular emission and low solubility in water. To address the problem in water sampling method, this study used passive samplers (PS) composed of silicon rubber sheets (SR) and speedisk (SD). SR and SD were used respectively to measure hydrophobic and hydrophilic organic pesticides. These were submerged in river water uninterruptedly for 34 days. Pesticides in PS were extracted and analysed by sensitive analytical instruments HPLC, GC-MS MS and LC-MS MS. Pesticide assessment were conducted in two river systems in Cagayan de Oro River Basin, Philippines where agricultural run-off are unintentionally and continuously disposed from medium to huge plantations. The samplers were able to measure 105 emerging organic pollutants of which, 56 were organic pesticides and 22 organochlorine pesticides (OCP). Out of 56 pesticides, 11 were measured beyond the applied threshold level of 10ng/L. These were boscalid, carbendazim, dimethomorph, metalaxyl, propiconazole, pyrimethanil, diuron, monuron, simazine, dichlorvos and phenamiphos. The 22 OCP, despite being banned or restricted for almost two decades, were measured in ultra-traces of $\mathrm{ng}-\mathrm{pg} / \mathrm{L}$. The data obtained in this study can be used to establish a baseline background level which is currently absent in most river systems in the Philippines. It is recommended that further study will be conducted using software PBPK or NORMTOX to assess health impacts and implications of the measured pesticides on the communities that are dependent, and continuously exposed to these constituents by these river waters.
\end{abstract}

Keywords:

Cagayan de Oro River Basin, GC-MS MS, LC-MS MS, passive samplers, pesticides

\section{Water Impact}

Organic pesticides from agricultural run-off in surface water is difficult to assess. Methodology used in this study, was able to measure organic and organochlorine pesticides in Cagayan de Oro River Basin, Philippines. Data can be used to evaluate health impacts and implications of the measured pesticides on the communities that are continuously exposed to these contaminants by these river waters. 


\section{Introduction}

There has been an overwhelming interest to monitor chemical pollutants in water resources after the implementation the Clean Water Act in 1972. This awareness came after the publication of the Silent Spring of Rachel Carson in 1962 about the adverse effect of indiscriminating usage of pesticides. Much attention was given to the persistent organic pollutants, POPs, because of their great potential to bio-accumulate and bio-magnify in the food chain. POPs were banned by the international environmental treaty, Stockholm Convention ${ }^{1}$. The prohibition was agreed and signed by participating countries, including the Philippines, in the convention that took effect as of May 2004.

The main problems in monitoring POPs is their very low dissolved water concentrations in the ppb $\left(10^{-9}\right)$ range or even lower. These low concentrations impose limitations on sensitive analytical instruments to measure potentially relevant organic pollutants in aqueous media and from irregular emission of organic pollutants which makes discrete or grab water sampling methods ineffective. Due to these limitations, POPs monitoring has been applied to sediments and tissues that excluded water samples. The tissue samples despite providing direct exposure measurements, failed to consider other chemical pollutants in the water, the organism's metabolism, bioaccumulation, avoidance and death ${ }^{2}$.

Due to these limitations mentioned, there was a need to develop an alternative sampling technique which provides an accurate estimate of POPs and other dissolved chemicals in water. Using passive samplers (PS) was an option to solve the problem ${ }^{3}$. PS can detect and measure irregular emission of pollutants, like pesticides. Furthermore, it can detect more substances than grab method on water samples taken at the same time. It is considered cost-effective, practical, more reliable, suitable for routine monitoring and can even detect low concentrations of organic compounds in the nano to picogram per liter (ng/L-pg/L) range which is difficult to attain in grab sampling method ${ }^{4}$.

This study aims to analyse pesticides unintentionally disposed and transported through surface runoff from farms in the upstream to receiving waters to assist in the establishment of baseline data. The pesticide assessment using the PS with be done in two river systems in Cagayan de Oro River Basin that headwaters to Mt. Kitanglad Mountain Range and head tails towards Cagayan de Oro River downstream.

For the review of literature in the advancement of passive sampling methods, the first passive sampling devices developed were air PS in the early $70 \mathrm{~s}^{3}$. Air PS was used to determine occupational exposure to volatile organic chemicals (VOC) in air. The extent of exposure was 
measured through diffusion of the VOC into the air samplers that enables the estimation of timeweighted average concentrations ${ }^{5}$. Two decades after its introduction, there has been a growing interest to use PS of quantifying ambient air pollutant concentrations, mostly in remote and wilderness areas ${ }^{6-8}$.

Various type of PS for air monitoring have been developed depending on their purpose. For example, an air sampler made of glass fiber filter infused with 2.4-dinitrophenylhydrazine (DNPH) and phosphoric acid fixed into an aerosol-sampling cassette was used to monitor formaldehyde in air with sensitivity of $5 \mathrm{ppb}$ for 15 minutes to eight hours sampling time ${ }^{9}$. Another air PS developed is the semipermeable membrane device (SPMD) filled with triolein that measured PCB and $\mathrm{HCH}$ in picogram per cubic meter $\left(\mathrm{pg} / \mathrm{m}^{-3}\right)^{7}$. Another air PS, Ogawa was developed with filterdiscs impregnated with citric acid as a useful tool for monitoring atmospheric ammonia, $\mathrm{NH}_{3}$, in poultry houses ${ }^{8}$. These air PS were validated, calibrated and continuously modified to be able to come up with an accurate and efficient sampling technique in monitoring pollutants in air ${ }^{10-12}$. The first patented passive sampling method in water was made by Byrne and Aylott in the 80s that used a nonpolar solvent in nonporous membrane ${ }^{13}$. The concept of PS was introduced by Soedergren using dialysis membranes filled with hexane solvent to stimulate the bioaccumulation of persistent lipophilic pollutants, like DDT, DDE or PCB from water ${ }^{14}$. To optimize Soedergren's concept, samples were tested in combinations of solvents and nonporous membranes for monitoring of organic pollutants. Which led to the development of neutral lipid triolein enclosed in a low-density polyethylene, LDPE tube. This device filled with lipid is referred to as a semipermeable membrane device, SPMD ${ }^{15}$.

SPMD was proven to be effective in measuring traces of POPs in ppt $\left(10^{-12}\right)$ in water. The estimated time-weighted average concentration of pollutants depends on the sampling rates and was determined in the laboratory under specific conditions ${ }^{16}$. To validate the effects of water temperature, turbulence and build-up of biofilm on membranes, SPMD were spiked with exposure standards which were not found in such environment, before deployment. The release rates of these standards were used as independent component for the kinetic exchange of SPMD and water ${ }^{17}$.

Results showed that standards added before deployment can predict the effect of environmental conditions on the uptake kinetics of hydrophobic organic compounds. The rate-limiting step in the diffusion process was the water boundary layer and not the membrane. The rate of diffusion through the SPMD is an isotropic process ${ }^{17}$. This findings laid to the foundation for the development of the performance reference compound approach, which is critical in improving the accuracy of time-weighted average concentration estimates from passive samplers ${ }^{18}$. 
117 Since SPMD has been introduced, numerous sampling devices for nonpolar organic 118 contaminants have been developed. Some of these are the LDPE strips, silicon strip, polymers 119 on glass, and solid-phase micro extraction (SPME) devices. All these developed samplers have a specific niche and were proven useful in environmental monitoring ${ }^{19}$.

In the later part of the 90s, a passive sampler was developed to complement SPMD. This lead to the development of the polar organic integrated sampler, POCIS. It contains triphasic admixture solid-phase adsorbents place in between sheets of microporous polyethersulfone membrane. It was tested in hydrophilic compounds like atrazine, diazinon and 17- $\alpha$-ethynylestradiol which were not readily measured in the other devices ${ }^{20}$. The triphasic admixture was later replaced with the universal sorbent, Oasis ${ }^{\circledR}$ HLB (Waters Corp), which was necessary to estimates in the timeweighted average concentrations ${ }^{21}$.

After the development of POCIS, there was a paradigm shift that showed the potential to assess various pharmaceutical, hormones and other organic contaminants ${ }^{22}$. Various PS are used depending on target contaminants, like POCIS (pharma or pesticide version), Empore Disk, Chemcatcher, Membrane enclosed silicon collector, Polyoxymethylene sheet, and many more ${ }^{23}$. Passive sampler use in this study are developed for more than a decade by Deltares, a research institute in the Netherlands ${ }^{24}$, that took into considerations the limitations and concerns of other PS previously tested. These PS consist of silicon rubber (SR) and speedisk sampler (SD) for nonpolar and polar organic compounds, respectively. These set of samplers are expected to give good estimates of ultra-trace organic pollutants in water at very concentrations of nanogram per liter ( $\mathrm{ng} / \mathrm{L})$ to even picogram per liter (pg/L). SD is made of hard propylene cage. It has an adsorption material and a filter made of glass fibre to retain the sorption material in the sampler. SR spiked with PAH and PCB compounds, was calibrated by using sheets of different surface area in two hydrodynamic conditions. Smaller surface area sheets were used to measure the uptake rate. In both hydrodynamic conditions, sampling rates $R_{s}$ is inversely proportional to $S R$ water partition coefficient, $\mathrm{K}_{\mathrm{pw}}$, with the equation $\mathrm{R}_{\mathrm{s}} \approx \mathrm{K}_{\mathrm{pw}}{ }^{-0.08}$. Under experimental conditions, modelling validates that the uptake of test compounds was controlled by the diffusion in water phase. The dissipation of PRC to target hydrophobic compounds, model using $R_{\mathrm{s}} \approx M^{-0.47}$ was suggested to estimate $R_{\mathrm{s}}$ by extrapolation ${ }^{25}$.

The measurement of concentrations of dissolved organic contaminants depend in the knowledge of in-situ sampling rates. Nonlinear least-squares (NLS) methods were used to estimate the sampling rates that take into account the information stored in PRC data which was not considered in the traditional methods. Errors of the traditional methods and the weighted and unweighted NLS were examined. Results showed that sampling rates are best estimated with 
unweighted NLS because of the availability of sampling rates estimates and uncertainties which the traditional method fails. Unweighted NLS also has smaller variability of sampling rate ${ }^{26}$. The most important measurement is using PS in the sampler-water partition coefficients $\mathrm{K}_{\mathrm{pw}}$ which are determined in the laboratory under standard conditions of $20^{\circ} \mathrm{C}$ for freshwater. $\mathrm{K}_{\mathrm{pw}}$ theoretically are dependent on environmental conditions like salinity and temperature. This Dutch SR was used to quantify the effects of these two factors. The location-specific SR-water partition coefficient, $\mathrm{K}_{\mathrm{sr}-\mathrm{w}}$, adjusted for temperature and salinity can be calculated based on the Dutch passive sampling field monitoring database gathered for 10 years using PAH and PCB data established on various locations ${ }^{27}$.

In this paper, the study site is in the Philippines, where agricultural expansion and intensification are practiced for the last two decades. Agribusiness is an economic shift mandated by laws and policies that emphasis on high quality cash crop production ${ }^{28}$. Despite all these natural calamities of at least 20 typhoons annually that destroy crops, the country is currently the world leading producers in abaca ( $87 \%$ of the world's market) and second, third and fourth respectively, in coconut, pineapple and banana. To produce these high quality cash crop for international market, it needs pesticides.

In agriculture, pesticides were developed and used for undeniable practical purposes. These are used to preserve crops and control infestations in order to have continuous production to cater the needs of the clients. But if pesticide application is mismanaged or overused it has the potential to cause harm to human and the environment. Worse, applied pesticides in farms are potential run-off in surface water of communities wherein pesticides were not even applied.

In Davao, Philippines, due to lack of awareness of banana planters on the adverse effect of pesticides and the lack of safety and protection, pesticides, dibromochloropropane, DBCP, was proven to cause sterility to about three thousand banana plantation workers ${ }^{29}$. In Northern Mindanao, Philippines, palm oil plantation owner was sued for not providing protective equipment to workers and the contamination of the water system experience by the communities near the plantations of pesticides furadan, glyphosate and paraquat ${ }^{30}$.

In order to avoid future pesticide-related dispute, baseline data on residual pesticides in some rivers along farms doing intensive agriculture is necessary. Northern Mindanao, is one of the regions where agricultural expansion and intensification are currently implemented. In some major rivers in the region, various funded researches on pesticide assessment were conducted for years using grab water sampling method ${ }^{31,32}$. But data gathered could not be considered as baseline information because of fluctuating results. To solve the problem of assessing irregular emission and low concentrations of residual pesticide in water, PS will be used instead of the traditional 
grab water sampling method. Pesticides assessment using passive samplers will also be conducted in Can Tho River, Vietnam, Mekong Delta ${ }^{33}$.

\section{Materials and methods}

\subsection{Location}

The research was conducted in Northern Mindanao, Philippines, where the major source of economy is agriculture. One of the major water resource is Mt. Kitanglad Mountain Range which is approximately 3,000 meter above sea level. The area of research was limited only to the two river systems, (1) Bubunawan River in Libona and (2) Cagayan de Oro River in Maasin with headtail from Mt. Kitanglad watershed. These rivers transverse towards Cagayan de Oro River in Cagayan de Oro City in the downstream.

The three sampling sites were in Lapinigan Creek, Bubunawan River Junction designated as S1; Maasin, Cagayan de Oro River midstream designated as S2 and Taguanaw-Lumbia Diversion; Cagayan de Oro River downstream designated as S3. Detailed location of the sampling sites are shown in Figure 1. S1 and S2 are along agricultural areas (mostly annual crops), while S3 is located along wooden grassland and near the residential areas.

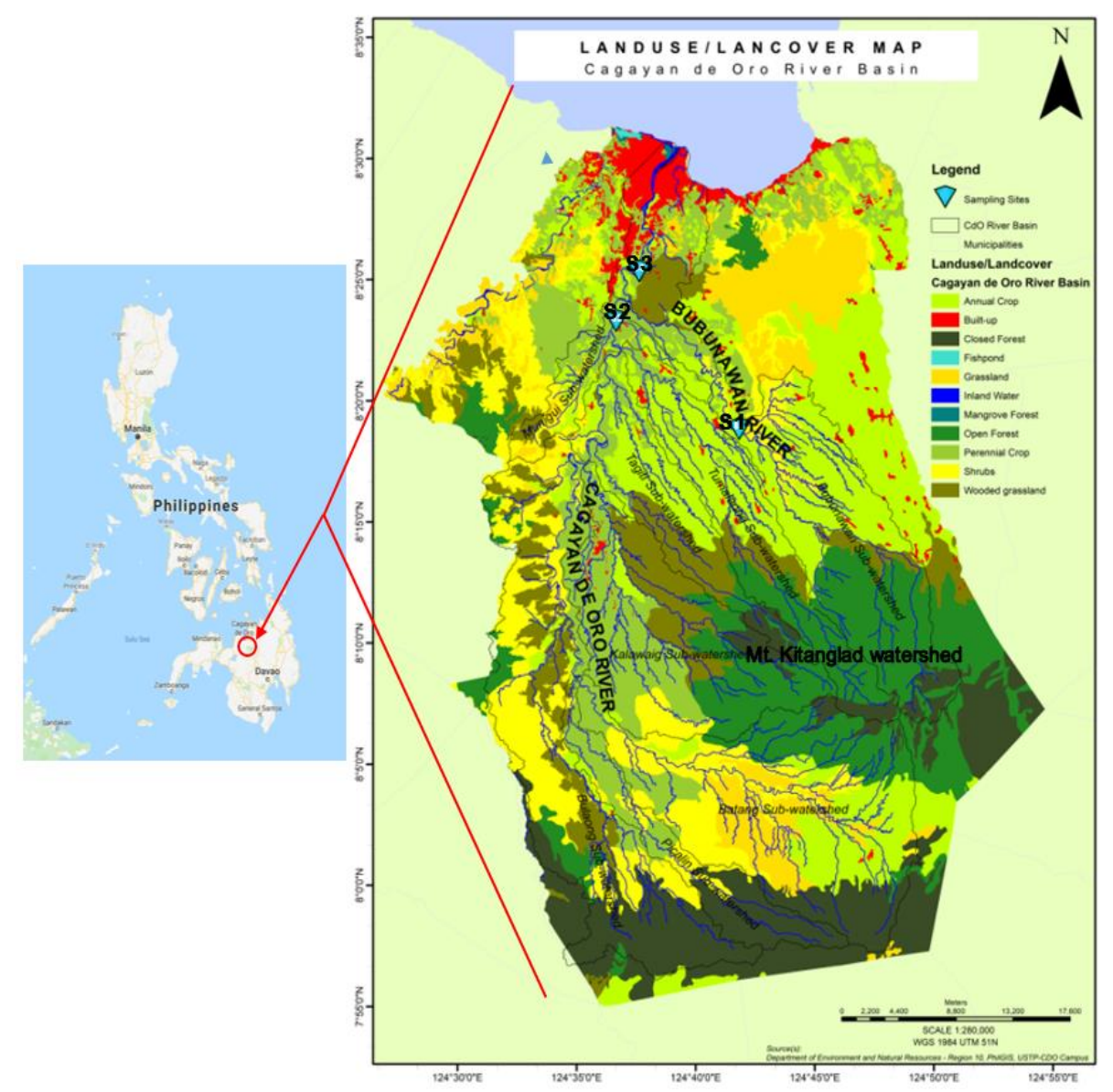

Figure 1 Sampling sites for the pesticide assessment. 
Before water sampling, SR were pre-cleaned for 100 hours using ethylacetate solvent in a soxhlet apparatus. The ethylacetate was removed by soaking the SR in methanol twice for eight (8) hours of approximately $4 \mathrm{~mL}$ of methanol per sheet. The SRs were then spiked with PRC. SD as an adsorption sampler was not pre-spiked with PRC. Samplers SR and SD were stored in glass containers until the actual sampling.

In the deployment, PS were composed of six (6) sheets of SR and three (3) pieces of SD. These were attached firmly in an iron post and submerged below the water surface at approximately 1.5 to 2.0 meters below the surface for uninterrupted 34 days. After sampling, the PS were dismantled. These are shown in Figure 2. The set of PS were kept in its original glass containers and stored at $-20^{\circ} \mathrm{C}$ before actual analyses.
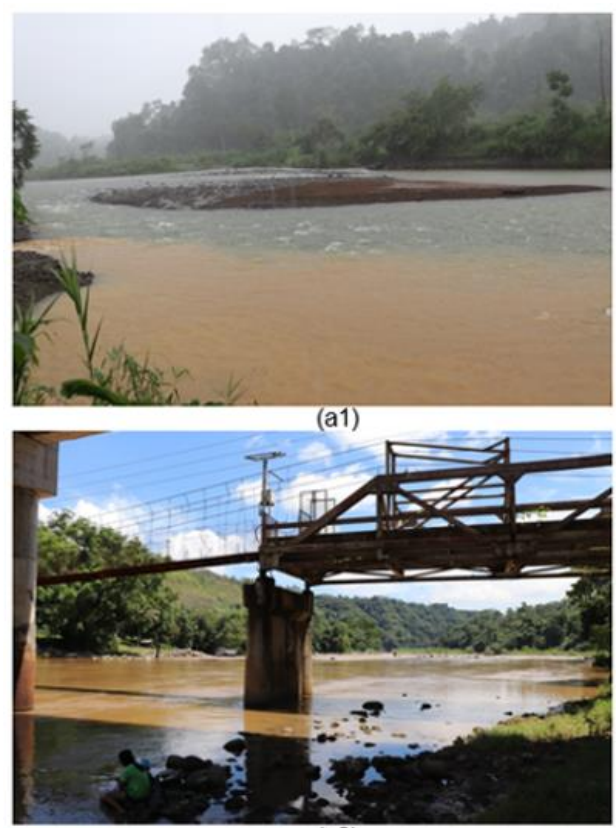

(a2)

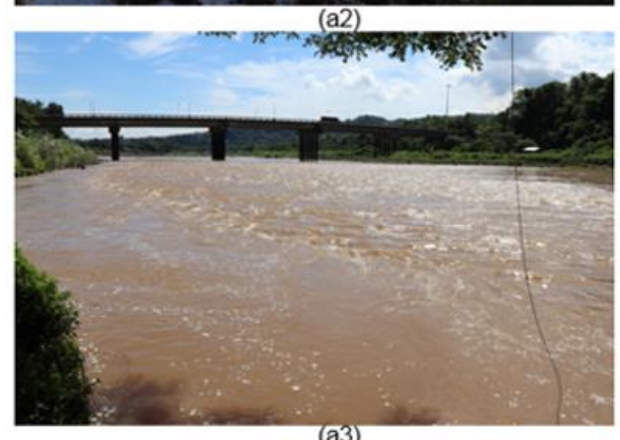

(a)

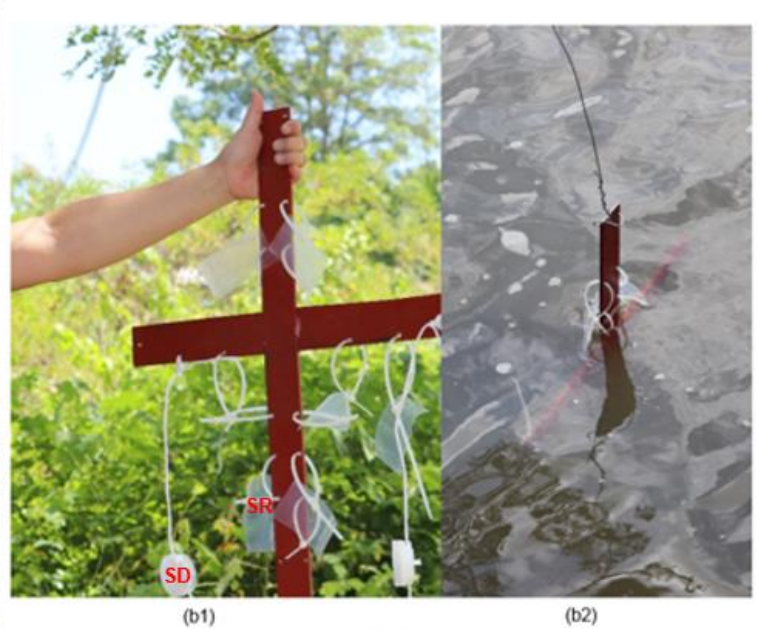

(b)

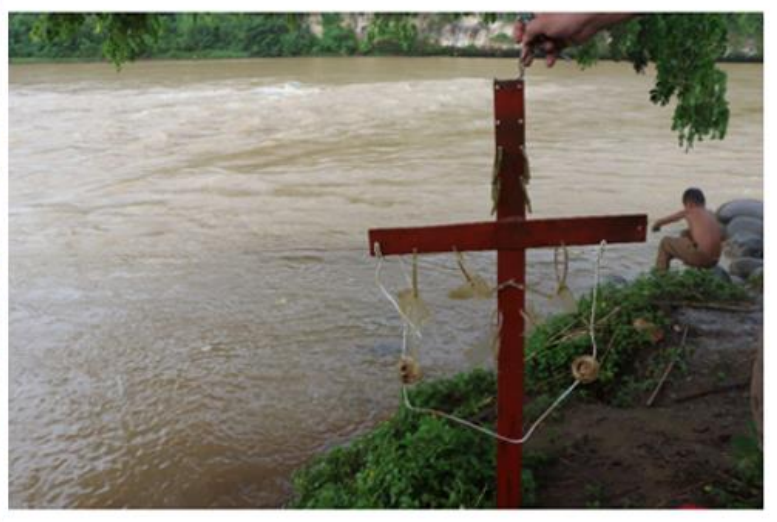

(c)

Figure 2 Passive samplers' installation, monitoring and dismantling.

Passive samplers were installed in three sampling sites (a). The sites were in Bubunawan River, Libona (a1), Cagayan de Oro River, Maasin (a2) and Cagayan de Oro River, Taguanaw (a3). For the installation (b), the samplers (b1) were composed of 6 silicon rubbers (SR) and 3 speedisks (SD) arranged in an iron stand and submerged in river water (b2). After 34 days, the iron stand with the samplers were removed for pesticide analyses (c). 
222 The deployment of PS started approximately two months after the raining season starts and 223 completed almost at the end of the raining season.

\subsection{Extraction and Analysis}

The preparations, extraction and chemical analysis were performed in the laboratory of the Department of Environmental Modelling, Sensing and Analysis (EMSA) of TNO in Utrecht, the Netherlands. Both samplers, SR and SD, were extracted by acetonitrile by dialysis, and successively, after mild evaporation, transferred into hexane for GC-MS MS analysis or redissolved in a defined volume of acetonitrile. Hydrophobic organic compounds and pre-spiked PRC on SR were analysed by GC-MS MS. Hydrophilic compounds were analysed by LC-MS MS.

The release model of Rusina (25) on the pre-spiked PRC on SR before deployment was used to calculate the freely dissolved concentrations in water and estimate the sampled volume. The freely dissolved concentrations and respective sampled volumes were calculated by integrating the freely dissolved concentrations of fluoranthene and pyrene from SR with the measured concentration in SD. These two compounds exhibits comparable behaviour in both samplers.

\subsection{Calculation}

237 The calculation for the aqueous concentrations of analytes used the formulas developed by Smedes and Booij (4). The water sampling rates were necessary and were calculated by the retained PRC fractions, which were ratios of the amount of PRC at the beginning and end of exposure. The PRC data were pre-screened before calculating the sampling rates. The detection limits from the extract may depend on the amount of other compounds present. PRC were carefully scrutinised for possible interferences. It can only be processed further if PRC peak showed no interferences.

244 The PRC fractions (f) can be calculated by the equation:

$$
f=\frac{N_{t}}{N_{0}}=\text { exponent }\left(-\frac{R_{s} t}{K_{p w} m}\right)
$$

Where $\mathrm{N}_{t}$ and $\mathrm{N}_{0}$ were respectively the dosed amount in the reference SR and the amount after exposure; $R_{s}$ is the equivalent water sampling rate (1/d), $t$ was the exposure time $(d)$, $m$ was the mass of the $S R(\mathrm{~kg})$ and $K_{p w}(1 / \mathrm{kg})$ was $S R$-water partition coefficient. The $K_{p w}$ can be obtained from Smedes (34). The degree of $R_{s}$ can be controlled by the passage of the water boundary layer as proven by Rusina (25) that $R_{s}$ decreases with increasing molar mass $(M)$.

$$
R_{S}=\frac{B}{M^{0.47}}
$$


where B was a proportionality constant that was proportional to the sampler's surface area.

Thus equation 1 becomes:

$$
f=\text { exponent }\left(-\frac{B t}{K_{p w} M^{0.47} m}\right)
$$

The absorbed organic compounds were calculated by the following equations given by Booij (35):

$$
\begin{gathered}
N_{t}=K_{p w} m C_{w}\left(1-\text { exponent }\left(-\frac{R_{s} t}{K_{p w} m}\right)\right) \\
C_{w}=\frac{N_{t}}{K_{p w} m\left(1-\text { exponent }\left(-\frac{R_{s} t}{K_{p w} m}\right)\right)}
\end{gathered}
$$

Then to use the proportionality constant $\mathrm{B}, \mathrm{C}_{\mathrm{w}}$ can be calculated by combining equations 2 and 5 to have a general equation 6 that incorporates the linear uptake, transition and equilibrium stages.

$$
C_{w}=\frac{N_{t}}{K_{p w} m\left(1-\text { exponent }\left(-\frac{B t}{K_{p w} M^{0.47} m}\right)\right)}
$$

The $\mathrm{K}_{\mathrm{pw}}$ values were necessary to PRCs and target organic compounds that approach equilibrium. $K_{p w}$ values can be obtained from Smedes (34).

\section{Results and discussion}

The study sites, Bubunawan and Cagayan de Oro Rivers are classified under Class $A$ by the Department of Environment of Natural Resources. Class A means a Public Water Supply Class II, which is intended as sources of water supply requiring conventional treatments, like coagulation, sedimentation, filtration and disinfection, to meet the Philippines National Standards for Drinking Water of $2017^{36}$. These PNSDW standards were obtained using grab water sampling method with various standardised analytical instruments. This study used different methodology, passive samplers (SR and SD), and analytical instruments GC-MS MS and LC-MS MS. Thus, instead of the set PNSDW standards, this study applied the $10 \mathrm{ng} / \mathrm{L}$ threshold level.

SR samplers spiked with PRC were capable of detecting 163 organic compounds, were able to measure 105 emerging organic pollutants in this study. These were composed of 56 organic pesticides, 7 polychlorinated biphenyls (PCB), 16 polycyclic aromatic hydrocarbons (PAH), 22 OCP and 4 antibiotics/pharmaceuticals. This paper is only limited to the 11 prevalent organic and organochlorine pesticides measured. For the complete list of emerging pollutants measured, please refer to the paper of Salingay (37). 


\subsection{Prevalent Organic Pesticides}

274 Of the 56 pesticides measured, 11 were beyond the applied threshold level of $10 \mathrm{ng} / \mathrm{L}$ as shown 275 in Table 1. The chemical structure of these prevalent pesticides are shown in Figure 3. These 276 organic pesticides are composed of one or more ring/s that is polysubstituted, except dichlorvos.

277 These are further categorise into its mode of action, as fungicides, herbicides, and insecticides.

278 Table 1 Concentration of prevalent pesticides measured in $\mathrm{ng} / \mathrm{L}$ per sampling site.

\begin{tabular}{lcccccc}
\hline & \multicolumn{2}{c}{ S 1 } & \multicolumn{2}{c}{ S 2 } & \multicolumn{3}{c}{ S 3 } \\
\cline { 2 - 7 } Pesticides & SR & SD & SR & SD & SR & SD \\
\hline Fungicides & & & & & & \\
$\quad$ Boscalid & 45 & 5 & 6 & $<1$ & 13 & 5 \\
$\quad$ Carbendazim & 11 & $>0.1$ & 5 & nd & nd & $>0.1$ \\
$\quad$ Dimethomorph E\&Z & 24 & $>0.1$ & $>1$ & nd & 4 & nd \\
$\quad$ Metalaxyl & 10 & nd & 20 & $>1$ & 17 & $>1$ \\
$\quad \begin{array}{l}\text { Propiconazole } \\
\quad \text { Pyrimethanil }\end{array}$ & 12 & $>1$ & 3 & nd & 4 & $>1$ \\
Herbicides & 203 & $<1$ & $>1$ & nd & 23 & $>1$ \\
$\quad$ Diuron & & & & & & \\
$\quad$ Monuron & 368 & 13 & 81 & 2 & 101 & 5 \\
$\quad$ Simazine & 15 & $>1$ & nd & nd & nd & nd \\
Insecticides & 158 & nd & 121 & nd & 125 & nd \\
$\quad$ Dichlorvos & & & & & & \\
$\quad$ Phenamiphos & 11 & nd & nd & nd & nd & nd \\
\hline nd not detected & 40 & 2 & 6 & $<0.1$ & 13 & $<1$ \\
\hline
\end{tabular}
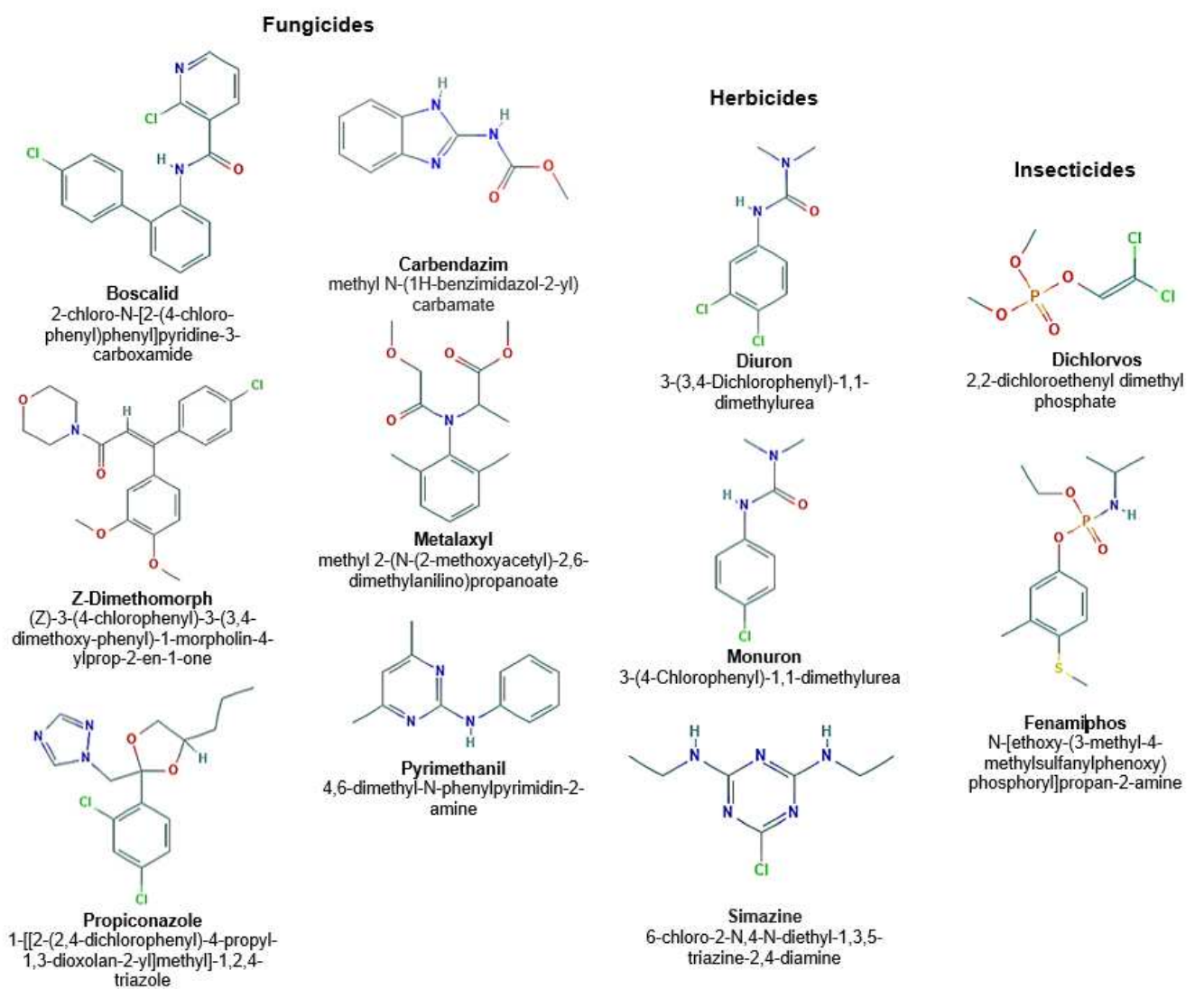
phosphate 


\subsubsection{Fungicides}

283 To eradicate or prevent the growth of fungi and its spores that damage plants, fungicides are used. These fungal diseases in plants can easily be spread and contaminate other plants when moist. Before applying fungicides, identification of these fungal diseases are important. In some cases, fungicides were created to prevent plant diseases and become ineffective if symptoms already developed ${ }^{38}$. Fungicides measure were boscalid, carbendazim, dimethomorph, metalaxyl, propiconazole and pyrimethanil.

Boscalid is a fungicide used against Alternaria spp., Botrytis spp. and Schlerotinia spp. that acts as enzyme succinate dehydrogenase inhibitor. Boscalid has solubility in water $\left(\mathrm{H}_{2} \mathrm{O}_{\text {sol }}\right)$ of $4.6 \mathrm{mg} / \mathrm{L}$ at $20^{\circ} \mathrm{C}$, has a half-life ( $\left.\mathrm{DT}_{50}\right)$ in soil of 104-224 days, non-volatile in water surfaces and dry soil 39. Boscalid was measured in all sampling sites and both samplers (SR and SD). Higher concentrations were measured in SR, which means hydrophobic. This can also be seen in its chemical structure in Figure 3, which shows three rings and polysubstituted.

Boscalid was measured in decreasing concentration of: $\mathrm{S} 1$ (50 ng/L) > S3 (18ng/L) > S2 (7 ng/L). Considering $\mathrm{H}_{2} \mathrm{O}_{\text {sol }}$ and $\mathrm{DT}_{50}$ in soil, the measured concentrations were most probably from soil absorption. Pesticides are usually applied during the dry season. During the wet season, constant raining in high lands enhanced soil erosion to loosely-held-soil crops.

Carbendazim is used to control diseases that include Fusarium and Septoria. At below $50^{\circ} \mathrm{C}$, it can be stable for 2 years or more and in acidic medium it will form water-soluble salts. As shown in its chemical structure, it is a benzimidazole, with methoxycarbonyl group attached to it. It was measured in all sampling sites with concentrations in decreasing order of: S1 $(11 \mathrm{ng} / \mathrm{L})>\mathrm{S} 2(5$ $\mathrm{ng} / \mathrm{L})>\mathrm{S} 3(0.2 \mathrm{ng} / \mathrm{L})$. It was measured higher in SR, except in S3 where it was only detected in SD. It is necessary to monitor carbendazim as when combined with sodium nitrite it is carcinogenic ${ }^{40}$. Carbendazim is classified by USEPA (41) as "possible human carcinogen," and banned for food uses in the US. It is also not approved for use in the EU ${ }^{42}$.

Dimethomorph is mixture of $E$ and $Z$ isomers in an unspecified ratio, where only the $Z$ isomer has fungicidal activity. It was measured in SR, except in $\mathrm{S} 1$, in a decreasing order of $\mathrm{S} 1(24 \mathrm{ng} / \mathrm{L})>$ S3 $(4 \mathrm{ng} / \mathrm{L})>\mathrm{S} 2(>1 \mathrm{ng} / \mathrm{L})$. S3 value was greatly influenced by the agricultural runoff from $\mathrm{S} 1$ than by S2. In case of photolysis, it would happened more in S3. As S1 and S2 are located in a much higher elevation and sunlight is limited only to 5-7 hours in a day or even less during the rainy season. Dimethomorph has limited information on its breakdown in surface water. Dimethomorph has three rings and polysubstituted in its structure, It is non-volatile in water, low soil mobility and leaching potential ${ }^{43}$. 
317 (10 ng/L). This shows that farms along and above S2 used metalaxyl more than farms in S1.

318 Metalaxyl in water, will not readily be adsorbed by sediments or suspended solids. Under 319 environmental conditions, it resists chemical hydrolysis. This can be seen in the complexity of its chemical structure as shown in Figure 3. It has $\mathrm{DT}_{50}$ of approximately 40 days, $\mathrm{H}_{2} \mathrm{O}_{\text {sol }}$ of $8.4 \times 10^{3}$ $\mathrm{mg} / \mathrm{L}$ at $22^{\circ} \mathrm{C}$ and degrades in the presence of humic acid with more than 60 hours of irradiation 44. Knowing its rate of degradation, most of metalaxyl in farms above S1 and S2 degraded before it was measured.

Propiconazole was measured in all sampling sites and both samplers, except in S2. The concentration in decreasing order is $\mathrm{S} 1(12 \mathrm{ng} / \mathrm{L})>\mathrm{S} 3(4 \mathrm{ng} / \mathrm{L})>\mathrm{S} 2(3 \mathrm{ng} / \mathrm{L})$. Propiconazole has $\mathrm{H}_{2} \mathrm{O}_{\text {sol }}$ of $100 \mathrm{mg} / \mathrm{L}$ at $25^{\circ} \mathrm{C}$. Propiconazole has been proven to be stable in water and soil environments as it does not readily reacts with water and air. The stability can be readily seen in its chemical structure in Figure 3. It got three rings and polysubstituted. It undergoes degradation of 40-70 days in aerobic soil, 25-85 days in water and 60-96 days in typical soils ${ }^{45}$. If applied on the dry season, the degradation process of propiconazole coincides, more or less, with the sampling period of this study.

Pyrimethanil was measured in all sampling sites and both samplers, except in S2. The highest concentration was obtained in S1 (204 ng/L) and a very low concentration in the other river system S2 (>1 ng/L). The concentration of $S 3(24 \mathrm{ng} / \mathrm{L})$ is obviously, mostly contributed by $\mathrm{S} 1$. Pyrimethanil as shown in Figure 3, is an aminopyrimidine. An aryl hydrocarbon receptor agonist with $\mathrm{H}_{2} \mathrm{O}_{\text {sol }}$ of $121 \mathrm{mg} / \mathrm{L}$ at $25^{\circ} \mathrm{C}$. Pyrimethanil degrades with a $\mathrm{DT}_{50}$ of $27-82$ days in soil experiments but degrades faster in field experiments of $D_{50} 7-54$ days ${ }^{46}$. Considering the DT $_{50}$ of pyrimethanil, the concentrations measured by samplers were just a small fraction of the original amount.

\subsubsection{Herbicides}

Herbicides are used to eliminate unwanted weeds. Its mode of action can be selective or nonselective. To safeguard the desired agricultural crops unaffected and only eliminate unwanted plants, selective herbicide should be used. After harvest when clearing lands is necessary, nonselective herbicide will be used as it kills almost any plant type. Herbicides can either act immediately or may take longer, like a week or more. Some even persist for a certain period of time in plants, soil, water or other organisms ${ }^{47}$. Herbicides measured were diuron, monuron, and simazine.

Diuron was measured in both samplers in all sampling sites. The concentrations obtained in decreasing order is; $\mathrm{S} 1(381 \mathrm{ng} / \mathrm{L})>\mathrm{S} 3(106 \mathrm{ng} / \mathrm{L})>\mathrm{S} 2(83 \mathrm{ng} / \mathrm{L})$. Higher concentrations in SR would mean hydrophobic, which is also shown in Figure 3 as a polysubstituted one ring compound. Diuron and its derivatives has $\mathrm{DT}_{50}$ of 1-12 months and 1-5 months, respectively. It 
has $\mathrm{H}_{2} \mathrm{O}_{\text {sol }}$ of $42 \mathrm{mg} / \mathrm{L}$ at $25^{\circ} \mathrm{C}$, But in pineapple farms, diuron residues stay three years after the application ${ }^{48}$. Considering the $\mathrm{DT}_{50}$ of diuron, the concentrations measured could be the sum of the recently applied or from the previous year/s.

Monuron was only measured in S1 and in both samplers with an obtained concentration of 15 $\mathrm{ng} / \mathrm{L}$. The no detection (nd) in S2 does not mean that farms along and above S2 were not using monuron. $\mathrm{DT}_{50}$ in soil ranges from less than 30 to 166 days, in surface water with natural sunlight is approximately 15 days and accelerated by surfactants ${ }^{49}$. Considering DT $_{50}$ of monuron, the concentration of monuron must be too small to be detected or probable diluted by the volume of water in the various river systems above S2. This holds true in S3 as well.

Simazine was measured only in SR. Which means hydrophobic as readily seen its structure in Figure 3, which is a polysubstituted triazine. The concentration obtained in decreasing order is; $\mathrm{S} 1(158 \mathrm{ng} / \mathrm{L})>\mathrm{S} 3(125 \mathrm{ng} / \mathrm{L})>\mathrm{S} 2(121 \mathrm{ng} / \mathrm{L})$. It does not readily absorb by soil but has the ability to leach and mostly likely to contaminate groundwater. DT $_{50}$ on sandy loam soil is $36-234$ days, 16-25 weeks on loamy sand and 75 days in other soil type. Residual simazine stays for 60-210 days after application since it absorbs to clays and wastes ${ }^{50}$. Simazine measured must be applied on the fields in the last two months or more due to the $\mathrm{DT}_{50}$ in clayish soil, the sampling time, $\mathrm{H}_{2} \mathrm{O}_{\text {sol }}$ of $6.2 \mathrm{mg} / \mathrm{L}$ at $20^{\circ} \mathrm{C}$.

\subsubsection{Insecticides}

In farms, to eliminate or control one or more insect species, insecticides are used. Insecticides mode of action can either be systemic, contact or ingested. Systemic insecticide can be applied through soil drenching, contact is used in aiming at target insects and ingested is when insecticide is placed on locations where insects can ingest it. Insecticides acts on the nervous system that disrupt the exoskeletons. But this mode of action can also pose risk to other non-target organisms, including humans ${ }^{51}$. Insecticides measured were dichlorvos, and phenamiphos.

Dichlorvos it was only measured in SR of $\mathrm{S} 1$ of concentration $11 \mathrm{ng} / \mathrm{L}$. The values obtained can be explained by the $\mathrm{H}_{2} \mathrm{O}_{\text {sol }}$ of $8.00 \times 10^{3} \mathrm{mg} / \mathrm{L}$ at $20^{\circ} \mathrm{C}$ and the rapid $\mathrm{DT}_{50}$ in soil of 7 days in both extreme $\mathrm{pH}$. Dichlorvos has the ability to leach into the ground within 5 days to a depth of $30 \mathrm{~cm}$. The rate of breakdown is fast in alkaline environment of $\mathrm{DT}_{50} 4.5$ hours at $\mathrm{pH} 9.1$ as compared to acidic environment of $\mathrm{DT}_{50}$ of 50 hours at $\mathrm{pH} 1.0{ }^{52}$. As shown in in its structure in Figure 3 , it is an aliphatic organophosphate compound. Unlike the other pesticides, it has no ring and highly volatile. Most of the dichlorvos applied on the field biodegraded or hydrolysed before it reach the sampling sites.

Phenamiphos was measured in all sampling sites and in both samplers. Concentration in decreasing order is; $\mathrm{S} 1(42 \mathrm{ng} / \mathrm{L})>\mathrm{S} 3(14 \mathrm{ng} / \mathrm{L})>\mathrm{S} 2(6 \mathrm{ng} / \mathrm{L})$. It has $\mathrm{H}_{2} \mathrm{O}_{\text {sol }}$ of $329 \mathrm{mg} / \mathrm{L}$ at $20^{\circ} \mathrm{C}$ and a $\mathrm{DT}_{50}$ range of $4-11$ days in four types of soils. If repeated application of phenamiphos were 
done, the degradation increases by 10 to 20 times higher compared to untreated soil ${ }^{53}$. Based on short $\mathrm{DT}_{50}$ ranges, phenamiphos measured must be from the repeated application.

In the Philippines, phenamiphos is a restricted pesticide since 1989, but can be used for banana and pineapple plantations ${ }^{54}$. It is restricted because some studies showed it is an acetylcholinesterase inhibitor but it is classified by USEPA as not carcinogenic for humans ${ }^{41,53}$.

In this study, the general trend of concentrations per sampling site of the 11 prevalent pesticides is in decreasing order of $\mathrm{S} 1>\mathrm{S} 3>\mathrm{S} 2$, except in metalaxyl, where S2 had higher concentrations. The eleven prevalent pesticides were all measured in S1, while monuron and dichlorvos were not detected in S2 and S3. It is also important to highlight the high values of pesticides boscalid, dimethomorph E \& Z, diuron, pyrimethanil, phenamiphos and simazine in S1. Pesticides diuron and simazine were measured high in SR samplers in all three sampling sites.

Residual organic pesticides measured in S1 and S2 are expected as these areas are surrounded with agricultural farms or plantations. The whole river basin has eight sub watersheds and covers the local government units of Baungon, Cagayan de Oro, Libona, and Talakag. With a land area for annual and perennial crops of almost 6,000 and 3,030 square $\mathrm{km}$, respectively.

There are important notes that should be considered in the 11 prevalent pesticides measured. Pyrimethanil was classified as possible human carcinogen ${ }^{46}$; diuron is known/likely to be human carcinogen ${ }^{55}$; carbendazim is banned in the US and EU, monuron is no longer registered in the US but manufactured for export ${ }^{49}$; simazine classified in 1989 as carcinogen but reclassified as not genotoxic in $2005^{56}$; dichlorvos was proposed by EPA in 1995 to cancel its usage but now classified by USEPA as probable human carcinogen ${ }^{57}$ and lastly, phenamiphos was declared restricted in the Philippines.

\subsection{Persistent Organic Pollutants POPs}

Organochlorine pesticides, OCP, are compounds classified under POPs. OCP were either banned or restricted for almost two decades in the Philippines ${ }^{54}$ in compliance with the Stockholm Convention agreement. OCP measured in this study in nano-traces are shown in Table 2. Looking closely on some of OCP chemical structures of some OCP shown in Figure 4, these are polychlorinated alicyclic or cyclodienes. OCP measured were aldrin, dieldrin, chlordane, dichlorodiphenyltrichloroethane (DDT), endosulfan, hexachlorocyclohexane $(\mathrm{HCH})$, heptachlor, heptachlor epoxide, hexachlorobenzene, hexachloro-1,3-butadiene and pentachlorobenzene.

Aldrin, in the presence of sunlight and bacteria will be converted to dieldrin. The $\mathrm{H}_{2} \mathrm{O}_{\text {sol }}$ of aldrin and dieldrin at $25^{\circ} \mathrm{C}$ are respectively $2.7 \times 10^{-2} \mathrm{mg} / \mathrm{L}$ and $1.95 \times 10^{-1} \mathrm{mg} / \mathrm{L}^{58}$. So often, these two compounds are treated as one. Aldrin was measured in decreasing order of $\mathrm{S} 3(<0.01 \mathrm{ng} / \mathrm{L})>\mathrm{S} 1$ and S2 $(>0.01 \mathrm{ng} / \mathrm{L})$. Dieldrin on the other hand has the decreasing order of $\mathrm{S} 1(<0.1 \mathrm{ng} / \mathrm{L})>\mathrm{S} 3$ 
$421 \quad(<0.01 \mathrm{ng} / \mathrm{L})>\mathrm{S} 2(\mathrm{nd})$. In both cases, sources of residual aldrin and dieldrin were high in S1 than 422 in S2. Both compounds were measured only in SR samplers. Aldrin and dieldrin were banned in 423 the Philippines since 1989 because of its adverse effect to human. Dieldrin has DT 50 of 424 approximately five (5) years. But in tropical conditions, oxidation is faster as well as the 425 disappearance of dieldrin through evaporation occurs within 30 days ${ }^{59}$.

426 Table 2 Concentration of organochlorine measured in $\mathrm{ng} / \mathrm{L}$ per sampling site.

\begin{tabular}{|c|c|c|c|c|c|c|}
\hline \multirow{2}{*}{$\begin{array}{l}\text { Organochlorine } \\
\text { Pesticides }\end{array}$} & \multicolumn{2}{|c|}{ S 1} & \multicolumn{2}{|c|}{ S 2} & \multicolumn{2}{|c|}{ S 3} \\
\hline & SR & SD & SR & SD & SR & SD \\
\hline Aldrin & $>0.01$ & nd & $>0.01$ & nd & $<0.01$ & nd \\
\hline Dieldrin & $<0.1$ & nd & n.d. & nd & $<0.01$ & nd \\
\hline Chlordane-cis ( $\alpha$ ) & $<0.01$ & nd & $>0.01$ & nd & $>0.01$ & nd \\
\hline Chlordane-trans ( $\mathrm{Y}$ ) & $<0.01$ & nd & n.d. & nd & $>0.01$ & nd \\
\hline DDD-o,p' & $>0.001$ & nd & $>0.001$ & nd & $>0.001$ & nd \\
\hline DDD-p,p' & $<0.001$ & nd & $<0.001$ & nd & $<0.001$ & nd \\
\hline DDE-o,p' & $<0.0001$ & nd & $<0.0001$ & nd & $<0.0001$ & nd \\
\hline DDE-p,p' & $>0.01$ & $<0.001$ & $<0.001$ & nd & $<0.001$ & nd \\
\hline DDT-o,p' & $<0.0001$ & nd & $<0.0001$ & $<0.001$ & $<0.0001$ & nd \\
\hline DDT-p,p' & $<0.001$ & $<0.01$ & $<0.001$ & $<0.01$ & $>0.001$ & $<0.01$ \\
\hline Endosulfan- $\alpha$ & $<0.01$ & nd & $<0.01$ & nd & $<0.01$ & nd \\
\hline Endosulfan-ß & $<0.1$ & nd & $>0.1$ & nd & $<0.1$ & nd \\
\hline Endosulfan sulphate & $>1$ & nd & $>1$ & nd & $>1$ & nd \\
\hline $\mathrm{HCH}-\alpha$ & $>0.01$ & nd & $>0.01$ & nd & $<0.001$ & nd \\
\hline $\mathrm{HCH}-\beta$ & nd & $<0.001$ & $>0.1$ & nd & n.d. & nd \\
\hline $\mathrm{HCH}-\delta$ & n.d. & nd & $>0.001$ & $<0.001$ & $<0.001$ & nd \\
\hline $\mathrm{HCH}-\gamma$ (lindane) & $<0.01$ & nd & $>0.01$ & nd & $>0.01$ & nd \\
\hline Heptachlor & $<0.001$ & nd & n.d. & nd & $<0.0001$ & nd \\
\hline Heptachlor exo-epoxide & $<0.1$ & $<0.01$ & $<0.001$ & nd & $<0.01$ & nd \\
\hline Hexachlorobenzene & $<0.001$ & nd & $<0.001$ & nd & $<0.001$ & nd \\
\hline Hexachloro-1,3-butadiene & $<0.0001$ & nd & 0.0001 & nd & $<0.0001$ & $>0.01$ \\
\hline Pentachlorobenzene & $>0.001$ & nd & $>0.001$ & nd & $>0.001$ & nd \\
\hline
\end{tabular}
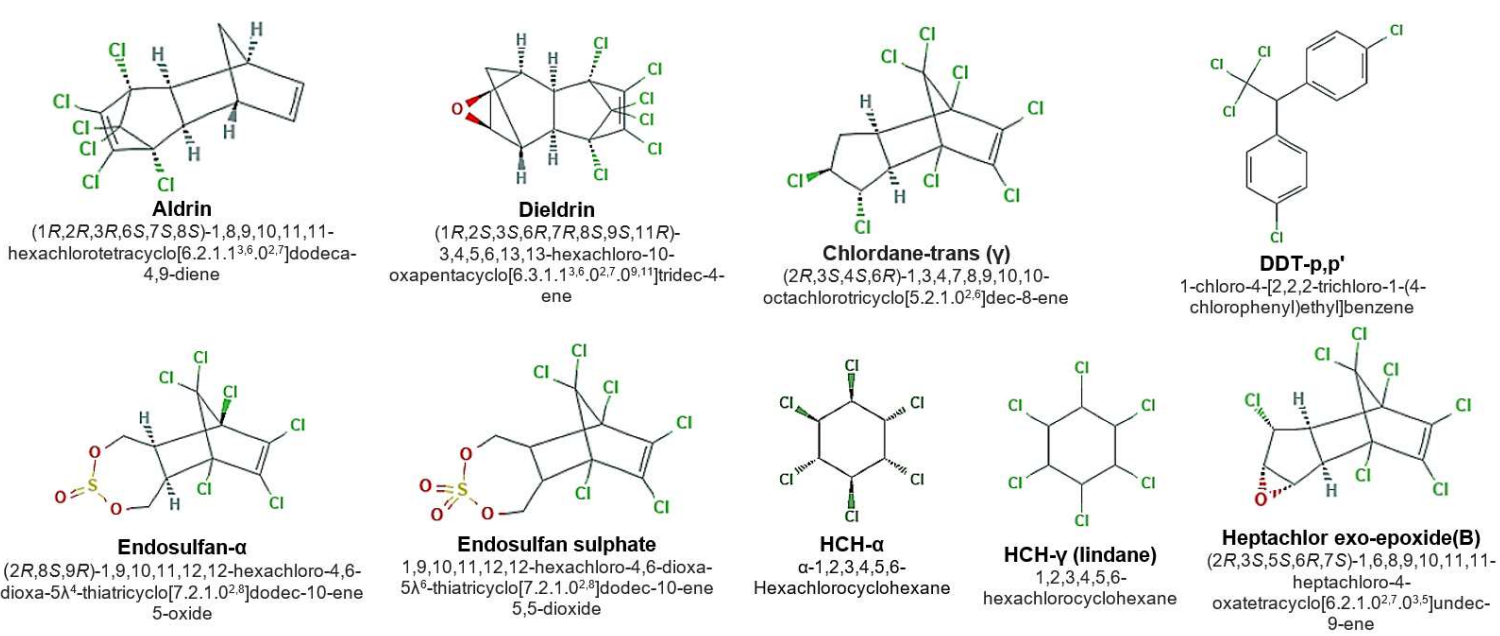

430 Figure 4 Structures of some organochlorine pesticides measured in traces of pg-ng/L 
431 Chlordane has $\mathrm{H}_{2} \mathrm{O}_{\text {sol }}$ of $5.6 \times 10^{-2} \mathrm{mg} / \mathrm{L}$ at $25^{\circ} \mathrm{C}$ and approximately half of it evaporates within $2-3$ 432 days. $\mathrm{DT}_{50}$ in soil of 350 days but can stay until 3500 days and if absorbed by organisms, is stored 433 in the body fats ${ }^{60}$. Chlordane were measured only in SD with decreasing order of $S 1(<0.01 \mathrm{ng} / \mathrm{L})$ $434>\mathrm{S} 3(0.01 \mathrm{ng} / \mathrm{L})>\mathrm{S} 2(>0.01 \mathrm{ng} / \mathrm{L})$. Chlordane was banned by the government in $1999{ }^{54}$. Even 435 after two decades, traces were still measured. It showed its persistence to stay in the environment.

436 DDT and metabolites DDE and DDE can exist in two forms, -p,p' or -o,p'. DDT has $\mathrm{H}_{2} \mathrm{O}_{\text {sol }}$ of 5.5 $437 \times 10^{3} \mathrm{mg} / \mathrm{L}$ at $25^{\circ} \mathrm{C}{ }^{61,62}$. DDT-p,p' was measured in all samplers while DDT-o,p' was detected in 438 all SR and only in the SD of S2. Higher values were obtained at SD samplers for DDT-p,p' of $439<0.01 \mathrm{ng} / \mathrm{L}$. Aside from DDT, metabolites DDE-o,p', DDE-p,p', DDD-o,p', and DDD-p,p' were also 440 measured. DDE and DDD in both forms were measured in SR, except DDE-p,p' in S1. The 441 concentrations of DDT and metabolites DDD and DDE were higher in the $-p, p^{\prime}$ forms. DDT was 442 banned in the Philippines in $2005^{54}$. But pico to nano traces of DDT and its metabolites in both 443 o,p' and -p,p' forms were still measured.

444 Endosulfan $-\alpha$ and $-\beta$ have $D_{50}$ of 60 and 800 days, respectively. While the oxidised form endosulfan sulfate has lower $\mathrm{DT}_{50}$ of approximately 40 days. Endosulfan can also hydrolysed at varying rates depending on the $\mathrm{pH}$ of the environment and much faster with the presence of ferric hydroxide ${ }^{63-65}$. Endosulfan stereoisomers, $-\alpha$, $-\beta$ and the oxidized form endosulfan sulphate were measured only in SR samplers in all sampling sites. The concentrations of endosulfan $-\alpha,-\beta$ and endosulfan sulphate summed up per sampling sites were all $>1.1 \mathrm{ng} / \mathrm{L}$. The approximate values is in the decreasing order of: S1 > S3 >S2. The oxidized form, endosulfan sulphate have higher concentrations in all sites. Endosulfan was a restricted pesticide for pineapple plantations in the Philippines until eventually banned in 2015 by the government ${ }^{54}$.

Hexachlorocyclohexane $(\mathrm{HCH})$ has eight isomers of which only four have commercial significance. These four isomers $\mathrm{HCH}-\alpha, \mathrm{HCH}-\beta, \mathrm{HCH}-\delta$ and $\mathrm{HCH}-\gamma$ (lindane) has $\mathrm{H}_{2} \mathrm{O}_{\text {sol }}$ at $25^{\circ} \mathrm{C}$ of $2.0 \mathrm{mg} / \mathrm{L}, 2.4 \times 10^{-1} \mathrm{mg} / \mathrm{L}, 31.4 \mathrm{mg} / \mathrm{L}$ and $7.3 \mathrm{mg} / \mathrm{L}$, respectively. The $\mathrm{DT}_{50}$ of $\mathrm{HCH}-\alpha$ and $\mathrm{HCH}$ $B$ is 7-8 years, while $\mathrm{HCH}-\gamma$ has only 65 hours ${ }^{66}$. These four isomers $\mathrm{HCH}-\alpha, \mathrm{HCH}-\beta, \mathrm{HCH}-\delta$ and $\mathrm{HCH}-\mathrm{\gamma}$ (lindane) were measured either in SR or SD or both. The concentrations of $\mathrm{HCH}$ (sum) per sampling sites is in decreasing order of: S2 $(>0.1 \mathrm{ng} / \mathrm{L})>\mathrm{S} 1(<0.01 \mathrm{ng} / \mathrm{L})>\mathrm{S} 3(>0.01 \mathrm{ng} / \mathrm{L})$. $\mathrm{HCH}$ was banned in the Philippines in 1989, except $\mathrm{HCH}-\gamma$ (lindane). $\mathrm{HCH}-\gamma$ is restricted for soil pre-plant application on pineapple plantations ${ }^{54}$. The two river systems transverse along pineapple plantations, measuring $\mathrm{HCH}-\gamma$ was expected.

Heptachlor oxidized by plants and animals forms heptachlor epoxide. Heptachlor has a $D_{50}$ of 463 six months to 3.5 years. But trace levels were detected even 14-16 years after application ${ }^{67}$. 464 Heptachlor and heptachlor epoxide (sum) concentrations in decreasing order is: $\mathrm{S} 1(<0.1 \mathrm{ng} / \mathrm{L})>$ 465 S3 $(<0.01 \mathrm{ng} / \mathrm{L})>\mathrm{S} 2(<0.001 \mathrm{ng} / \mathrm{L})$. Heptachlor epoxide was detected in S2 but not heptachlor. 
Heptachlor and heptachlor epoxide were measured in SR samplers, except heptachlor in S2 and

467 heptachlor epoxide was measured in SD in S1. Heptachlor was banned by the government in $1989^{54}$. Few years ahead of the worldwide prohibition.

Hexachlorobenzene was used as fungicide with $\mathrm{H}_{2} \mathrm{O}_{\text {sol }}$ of $4.7 \times 10^{-3} \mathrm{mg} / \mathrm{L}$ at $25^{\circ} \mathrm{C}$. It is very stable even if exposed to acidic and basic conditions. Trace concentrations of hexachlorobenzene is necessary to be monitored as chronic exposure will result to liver disease associated with skin lesions and human carcinogen associated with thyroid, kidney and liver cancer ${ }^{68}$. It was measured in SR of all sites of concentration of $<1.0 \times 10^{-3} \mathrm{ng} / \mathrm{L}$.

Hexachloro-1,3-butadiene was commonly used as solvent in making lubricants. $\mathrm{H}_{2} \mathrm{O}_{\text {sol }}$ is $3.20 \mathrm{mg} / \mathrm{L}$ at $25^{\circ} \mathrm{C}$. DT 50 is approximately 117 days ${ }^{69}$. The concentrations of hexachloro-1,3butadiene in SR in all sampling sites were approximately $1.0 \times 10^{-4} \mathrm{ng} / \mathrm{L}$ and $1.0 \times 10^{-2} \mathrm{ng} / \mathrm{L}$ in SD in S3. Considering the $\mathrm{DT}_{50}$ of hexachloro-1,3-butadiene and being banned for more than a decade, measuring in trace amounts show its persistence to stay in the environment. More importantly, this compound is considered potentially occupational carcinogenic ${ }^{70}$.

Pentachlorobenzene was used as fungicide and flame retardant. Incompatible with strong reducing and oxidizing agents and relatively unreactive with $\mathrm{H}_{2} \mathrm{O}_{\text {sol }}$ of $8.3 \times 10^{-1} \mathrm{mg} / \mathrm{L}$ at $25^{\circ} \mathrm{C}$ and $\mathrm{DT}_{50}$ of 74 days. In animal studies, it show that long term exposure have effects on liver and possible effect to human reproduction or development ${ }^{71}$. It was measured in SR of all sites of $>1.0 \times 10^{-3} \mathrm{ng} / \mathrm{L}$. It is necessary to monitor pentachlorobenzene due to its chronic effect to human liver and reproduction after years of constant exposure to it.

In this study, the general trend of concentrations per sampling site of OCP is in decreasing order of $\mathrm{S} 1>\mathrm{S} 3>\mathrm{S} 2$, except $\mathrm{HCH}$, where $\mathrm{S} 2$ had higher trace concentrations. OCP were measured in one organic form or another and measured in either SR or SD or both samplers, with some exceptions. $\mathrm{HCH}-\delta$ was not detected in $\mathrm{S} 1$, dieldrin, chlordane- $y$ and heptachlor were not detected in S2 and HCH-ß was not detected in S3. Nano-pico traces of OCP that were banned or restricted for almost two decades shows its persistence to stay in the environment for years or probably some farmers were still using it after the government prohibition.

Generally, the concentrations of prevalent organic pesticides in $\mathrm{ng} / \mathrm{L}$ and traces of banned OCP in $\mathrm{ng}-\mathrm{pg} / \mathrm{L}$ are within the controllable level of river water contaminations. The results showed a good soil absorption capacity of the region. Aside from pesticides, the farmers apply also fertilizers to condition the soil to yield quality crops. It should be considered that this region, where the study was conducted is mostly run by large and medium size land owners, where good agricultural practices are in place, necessary to produce crops for international market ${ }^{37}$. 


\section{Conclusion and recommendation}

500 The passive samplers, SR and SD, developed by Deltares and analysed with highly sensitive 501 analytical instruments, GC-MS MS and LC-MS MS, were able to measure 56 organic pesticide 502 contaminants in $\mathrm{ng} / \mathrm{L}\left(10^{-9} \mathrm{~g} / \mathrm{L}\right)$ and traces of 22 banned OCP in $\mathrm{ng} / \mathrm{L}$ to $\mathrm{pg} / \mathrm{L}\left(10^{-9} \mathrm{~g} / \mathrm{L}\right.$ to $\left.10^{-12} \mathrm{~g} / \mathrm{L}\right)$. 503 The methodology used in this study showed the effectiveness in measuring irregular and very low 504 concentrations of pollutants in river water.

505 Results show that agricultural expansion and intensification of the farms above and along the two 506 river systems produced agricultural runoff contaminated with multiple residual pesticides. 507 Although within a controllable level, it is still necessary to have regular pesticide monitoring and 508 evaluation. As these residual pesticides were also measured on Cagayan de Oro River 509 (downstream), where these pesticides were not even applied.

510 Since the country experiences pesticide-related disputes with farm owners and workers in the 511 past and recent past, baseline data is necessary to avoid conflict in the future. The data obtained 512 in this study can be used as basis to establish baseline data by concerned government agencies 513 for the amendments or implementation of existing environmental laws.

514 It is recommended that in environmental monitoring of pesticides, PS should be used instead of 515 the traditional grab sampling method and analyzed with sensitive analytical instruments of low 516 detection limits like GC-MS MS and LC-MS MS. Monitoring the concentrations of residual 517 pesticides is necessary not only to assess the acute and chronic effects to farmers and 518 communities within the vicinities of the farms but also the chronic effect on the communities along 519 the river systems that have been constantly exposed to small quantities for years.

520 It is further recommended to conduct further study on the health impact assessment and 521 implications of the measured pesticides on the communities that are dependent and continuously 522 exposed by these constituents by these river waters using software like Physiologically Based 523 Pharmacokinetic (PBPK) or NORMTOX.

\section{Declaration}

525 Availability of data and materials. The necessary datasets are already presented in this paper. Competing interests. The authors declare that they do not have competing interests. Funding. This work was supported financially by the Netherlands Fellowship Programme and Schlumberger Foundation Faculty for the Future under project number 106275. 
DG assisted in the preparations, data analysis and editing of the manuscript. CZ assisted in the searching for the research funds of the research, analysis and editing of the manuscript.

532

533

\section{Acknowledgements}

Technical support was extended by Deltares, TNO Laboratories, Utrecht, the Netherlands.

\section{Author's information}

\section{Maria Luisa Baiño Salingay \\ o PhD Research Fellow}

Civil Engineering and Geosciences, Technische Universiteit Delft (TU Delft), Building 23, Stevinweg1, 2628 CN Delft, the Netherlands

Coastal \& Urban Risk \& Resilience Department, IHE-Delft, Institute for Water Education, Westvest 72611 AX, Delft, the Netherlands

\section{- Associate Professor in Chemistry}

University of Science and Technology of Southern Philippines, Cagayan de Oro City, 9000 Philippines

Emails: M.L.Salingay@tudelft.nl; m.salingay@uh-ihe.org; maria.salingay@ustp.edu.ph

\section{Daniel Giesen}

- Scientific consultant

Deltares, Subsurface and groundwater quality, Postbus 85467, 3508 AL Utrecht, the Netherlands

Email: Daniel.Giesen@deltares.nl

\section{Chris Zevenbergen}

\section{- Professor}

Civil Engineering and Geosciences, Technische Universiteit Delft (TU Delft), Building 23, Stevinweg1, 2628 CN Delft, the Netherlands

Coastal \& Urban Risk \& Resilience Department, IHE-Delft, Institute for Water Education, Westvest 72611 AX, Delft, the Netherlands

Emails: c.zevenbergen@un-ihe.org; c.Zevenbergen@tudelft.nl 
1. Lallas PL. The Stockholm Convention on Persistent Organic Pollutants. American Journal of International Law. 2001;95(3):692-708.

2. Alvarez DA. Development of semipermeable membrane devices (SPMD s) and polar organic chemical integrative samplers (POCIS) for environmental monitoring. Environmental Toxicology and Chemistry. 2013;32(10):2179-81.

3. Vrana B, Allan IJ, Greenwood R, Mills GA, Dominiak E, Svensson K, et al. Passive sampling techniques for monitoring pollutants in water. TrAC Trends in Analytical Chemistry. 2005;24(10):84568.

4. Smedes F, Booij K. Guidelines for passive sampling of hydrophobic contaminants in water using silicone rubber samplers: International Council for the Exploration of the Sea; 2012.

5. Carmichael GR, Ferm M, Thongboonchoo N, Woo J-H, Chan LY, Murano K, et al. Measurements of sulfur dioxide, ozone and ammonia concentrations in Asia, Africa, and South America using passive samplers. Atmospheric Environment. 2003;37(9):1293-308.

6. Krupa SV, Legge AH. Passive sampling of ambient, gaseous air pollutants: an assessment from an ecological perspective. Environmental Pollution. 2000;107(1):31-45.

7. Ockenden WA, Sweetman AJ, Prest HF, Steinnes E, Jones KCJES, Technology. Toward an understanding of the global atmospheric distribution of persistent organic pollutants: The use of semipermeable membrane devices as time-integrated passive samplers. 1998;32(18):2795-803.

8. Roadman MJ, Scudlark JR, Meisinger JJ, Ullman WJ. Validation of Ogawa passive samplers for the determination of gaseous ammonia concentrations in agricultural settings. Atmospheric Environment. 2003;37(17):2317-25.

9. Levin JO, Lindahl R, Andersson K. A passive sampler for formaldehyde in air using 2,4dinitrophenylhydrazine-coated glass fiber filters. Environmental Science \& Technology. $1986 ; 20(12): 1273-6$.

10. Ayers GP, Keywood MD, Gillett R, Manins PC, Malfroy H, Bardsley T. Validation of passive diffusion samplers for SO2 and NO2. Atmospheric Environment. 1998;32(20):3587-92.

11. Hazrati S, Harrad S. Calibration of polyurethane foam (PUF) disk passive air samplers for quantitative measurement of polychlorinated biphenyls (PCBs) and polybrominated diphenyl ethers (PBDEs): Factors influencing sampling rates. Chemosphere. 2007;67(3):448-55.

12. Tang Y, Cape J, Sutton MJTSWJ. Development and types of passive samplers for monitoring atmospheric NO2 and NH3 concentrations. 2001;1:513-29.

13. Byrne B, Aylott R, inventorsConcentrator for removing organic materials from aqueous systems. British Patent 1566253. London, UK1980.

14.Soedergren A. Solvent-filled dialysis membranes simulate uptake of pollutants by aquatic organisms. Environmental Science \& Technology. 1987;21(9):855-9.

15. Huckins JN, Tubergen MW, Manuweera GK. Semipermeable membrane devices containing model lipid: A new approach to monitoring the bioavaiiability of lipophilic contaminants and estimating their bioconcentration potential. Chemosphere. 1990;20(5):533-52.

16. Huckins JN, Manuweera GK, Petty JD, Mackay D, Lebo JAJEs, technology. Lipid-containing semipermeable membrane devices for monitoring organic contaminants in water. 1993;27(12):248996.

17. Booij K, Sleiderink HM, Smedes F. Calibrating the uptake kinetics of semipermeable membrane devices using exposure standards. Environmental Toxicology and Chemistry. 1998;17(7):1236-45.

18. Huckins JN, Petty JD, Lebo JA, Almeida FV, Booij K, Alvarez DA, et al. Development of the permeability/performance reference compound approach for in situ calibration of semipermeable membrane devices. 2002;36(1):85-91.

19. Huckins JN, Petty JD, Booij K. Monitors of organic chemicals in the environment: semipermeable membrane devices: Springer Science \& Business Media; 2006.

20.Alvarez DA. Development of an integrative sampling device for hydrophilic organic contaminants in aquatic environments: University of Missouri-Columbia; 1999.

21. Alvarez DA, Petty JD, Huckins JN, Jones-Lepp TL, Getting DT, Goddard JPa, et al. Development of a passive, in situ, integrative sampler for hydrophilic organic contaminants in aquatic environments. Environmental Toxicology and Chemistry. 2004;23:1640-8.

22. Kolpin DW, Furlong ET, Meyer MT, Thurman EM, Zaugg SD, Barber LB, et al. Pharmaceuticals, Hormones, and Other Organic Wastewater Contaminants in U.S. Streams, 1999-2000: A National Reconnaissance. Environmental Science \& Technology. 2002;36(6):1202-11.

23. Vrana B, Komancová L, Sobotka J. Calibration of a passive sampler based on stir bar sorptive extraction for the monitoring of hydrophobic organic pollutants in water. Talanta. 2016;152:90-7. 
24.Deltares. Passive sampling for the effective monitoring of pollutants in water The Netherlands: Deltares; 2019 [

25.Rusina TP, Smedes F, Koblizkova M, Klanova J. Calibration of Silicone Rubber Passive Samplers: Experimental and Modeled Relations between Sampling Rate and Compound Properties. Environmental Science \& Technology. 2010;44(1):362-7.

26. Booij K, Smedes F. An improved method for estimating in situ sampling rates of nonpolar passive samplers. Environmental science \& technology. 2010;44(17):6789-94.

27.Jonker MTO, van der Heijden SA, Kotte M, Smedes F. Quantifying the Effects of Temperature and Salinity on Partitioning of Hydrophobic Organic Chemicals to Silicone Rubber Passive Samplers. Environmental Science \& Technology. 2015;49(11):6791-9.

28. Pulhin JM, Anthony MG, Ramirez MA. National Updates on Agribusiness Large Scale Land Acquisitions in Southeast Asia Brief \#4 of 8: Republic of the Philippines. 2011.

29. Chen M. Filipino Banana Workers Frustrated in Battle Over Dole's Pesticides. In These Times. 2012.

30.Umil AMD. Groups want palm oil toxic pesticides banned. Bulatlatcom. 2015 May 22, 2015.

31.Salingay MLB, Barber GM, Apdian JA, editors. Quantitative Determination of Pesticide Concentration and Other Water Quality Parameter in Bubunawan River and Lapinigan Creek of Libona, Bukidnon, Philippines. 4th International Congress of Chemistry and Environment or ICCE-2009; 2010; Ubonratchathani, Thailand.

32.Nalla C, Narisma L, Tabla V, Salingay ML, editors. Monitoring and Evaluation in terms of pesticides concentration and Other Water quality Parameters of Lapinigan Creek on Bubunawan River in Libona, Bukidnon, Philippines. 3rd International Conference on Environmental Education Network of the Philippines; 2010 February 2010; Davao City, Philippines.

33.Salingay MLB, Zevenbergen C, Giesen D. Pesticide assessment using passive samplers in Can Tho River, Vietnam, Mekong Delta. Manuscript submitted for publication. 2020.

34.Smedes F, Geertsma RW, Zande Tvd, Booij K. Polymer-Water Partition Coefficients of Hydrophobic Compounds for Passive Sampling: Application of Cosolvent Models for Validation. Environmental Science \& Technology. 2009;43(18):7047-54.

35. Booij K, Vrana B, Huckins JN. Theory, modelling and calibration of passive samplers used in water monitoring: Chapter 72007.

36.DENR. Water Quality Guidelines and General Effluent Standards of 2016, DENR Administrative Order No. 2016-08. In: Resources DoEaN, editor. Phlippines2016.

37. Salingay MLB, Rijke J, Pathirana A, Zevenbergen C. Effects of agricultural intensification and farmers' pesticide knowledge on water quality; insights from the Cagayan de Oro River, Philippines. Manuscript submitted for publication. 2020.

38.NPIC. Fungicides United States: Oregon State University and the US Environmental Protection Agency; 2019 [Available from: http://npic.orst.edu/ingred/ptype/fungicide.html.

39. PubChem Compound Summary for CID 213013, Boscalid [Internet]. National Center for Biotechnology Information. 2019. Available from: https://pubchem.ncbi.nlm.nih.gov/compound/Boscalid.

40. PubChem Compound Summary for CID 25429, Carbendazim [Internet]. National Center for Biotechnology Information. 2019. Available from: https://pubchem.ncbi.nlm.nih.gov/compound/Carbendazim.

41. USEPA. Chemicals Evaluated for Carcinogenic, Potentail Annual Cancer Report 2018. In: U.S. Environmental Protection Agency OoPP, editor. USA: US Environmental Protection Agency; 2018.

42.Carbendazim (Ref:BAS 346F) [Internet]. University of Hertfordshire. 2019. Available from: https://sitem.herts.ac.uk/aeru/ppdb/en/Reports/116.htm.

43. PubChem Compound Summary for CID 5889665, Dimethomorph E [Internet]. National Center for Biotechnology Information. 2019. Available from: https://pubchem.ncbi.nlm.nih.gov/compound/E Dimethomorph.

44.PubChem Compound Summary for CID 42586, Metalaxyl [Internet]. National Center for Biotechnology Information. 2019. Available from: https://pubchem.ncbi.nlm.nih.gov/compound/metalaxyl.

45. PubChem Compound Summary for CID 43234, Propiconazole [Internet]. National Center for Biotechnology Information. 2019. Available from: https://pubchem.ncbi.nlm.nih.gov/compound/Paclobutrazol.

46. PubChem Compound Summary for CID 91650, Pyrimethanil [Internet]. National Center for Biotechnology Information. 2019. Available from: https://pubchem.ncbi.nlm.nih.gov/compound/Pyrimethanil.

47.NPIC. Weed Control and Herbicides United States: Oregon State University and US Environmental Protection Agency; 2020 [Available from: http://npic.orst.edu/pest/weeds.html. 
48. Extension Toxicology Network. Diuron USA: PMEP, Cornell University; 1993 [Available from: http://pmep.cce.cornell.edu/profiles/extoxnet/dienochlor-glyphosate/diuron-ext.html.

49. PubChem Compound Summary for CID 8800, Monuron [Internet]. National Center for Biotechnology Information. 2019. Available from: https://pubchem.ncbi.nlm.nih.gov/compound/Monuron.

50.Extension Toxicology Network. Simazine USA: PMEP, Cornell University; 1993 [Available from: http://pmep.cce.cornell.edu/profiles/extoxnet/pyrethrins-ziram/simazine-ext.html.

51.NPIC. Insecticides United States: Oregon State University and the US Environmental Protection Agency; 2019 [Available from: http://npic.orst.edu/ingred/ptype/insecticide.html.

52. Extension Toxicology Network. Dichlorvos USA: PMEP, Cornell University; 1993 [Available from: http://pmep.cce.cornell.edu/profiles/extoxnet/carbaryl-dicrotophos/dichlorvos-ext.html.

53. PubChem Compound Summary for CID 31070, Fenamiphos [Internet]. National Center for Biotechnology Information. 2019. Available from: https://pubchem.ncbi.nlm.nih.gov/compound/fenamiphos.

54.FPA. Pesticide Regulatory Data. In: Authority FaP, editor. Quezon City, Philippines: Department of Agriculture; 2019.

55. Huovinen M, Loikkanen J, Naarala J, Vähäkangas K. Toxicity of diuron in human cancer cells. Toxicology in Vitro. 2015;29(7):1577-86.

56. NCBI. PubChem Compound Summary for CID 5216, Simazine 8600 Rockville Pike, Bethesda, MD20894, USA: National Center for Biotechnology Information; 2019 [Available from: https://pubchem.ncbi.nlm.nih.gov/compound/Simazine.

57.PubChem Compound Summary for CID 3039, Dichlorvos [Internet]. National Center for Biotechnology Information. 2019. Available from: https://pubchem.ncbi.nlm.nih.gov/compound/Dichlorvos.

58. PubChem Compound Summary for CID 12310947, Aldrin [Internet]. National Center for Biotechnology Information. 2019. Available from: https://pubchem.ncbi.nlm.nih.gov/compound/Aldrin\#section=3D-Conformer.

59. World Health O, International Programme on Chemical S. Aldrin and dieldrin : health and safety guide. Geneva: World Health Organization; 1989.

60.PubChem Compound Summary for CID 5993, Chlordane [Internet]. National Center for Biotechnology Information. 2019. Available from: https://pubchem.ncbi.nlm.nih.gov/compound/chlordane.

61.PubChem Compound Summary for CID 13089, o,p'-DDT [Internet]. 2019. Available from: https://pubchem.ncbi.nlm.nih.gov/compound/o $p$-ddt.

62. PubChem Compound Summary for CID 3036, p.p'-DDT [Internet]. National Center for Biotechnology Information. 2019. Available from: https://pubchem.ncbi.nlm.nih.gov/compound/DDT.

63.FAO. FAO PESTICIDE DISPOSAL SERIES 8, Rome: Food and Agriculture Organization of the United Nations; 2000 [

64.PubChem Compound Summary for CID 13940, Endosulfan sulfate [Internet]. National Center for Biotechnology Information,. 2020. Available from: https://pubchem.ncbi.nlm.nih.gov/compound/Endosulfan-sulfate.

65. PubChem Compound Summary for CID 3224, Endosulfan [Internet]. National Cneter for Biotechnology Information. 2019. Available from: https://pubchem.ncbi.nlm.nih.gov/compound/Endosulfan.

66. Toxic Substances Portal: Hexachlorocyclohexane [Internet]. Agency for Toxic Substances \& Disease Registry. 2005.

67. EXTOXNET: Heptachlor [Internet]. 1993.

68.PubChem Compound Summary for CID 8370, Hexachlorobenzene [Internet]. National Center for Biotechnology Information. 2019. Available from: https://pubchem.ncbi.nlm.nih.gov/compound/Hexachlorobenzene.

69. HSDB: Hexachloro-1,3-butadiene [Internet]. U.S. National Library of Medicine, National Institutes of Health, Health \& Human Services. 2014. Available from: https://toxnet.nlm.nih.gov/cgibin/sis/search2/r?dbs+hsdb:@term+@rn+@rel+87-68-3.

70. NIOSH. NIOSH List of Antineoplastic and Other Hazardoues Drugs in Healthcare Settings, 2016. In: Services DoHaH, editor. Washington DC, USA: National Insitutue for Occupational Safety and Health; 2016.

71.PubChem Compound Summary for CID 11855, Pentachlorobenzene [Internet]. National Center for Biotechnology Information. 2019. Available from: https://pubchem.ncbi.nlm.nih.gov/compound/pentachlorobenzene. 


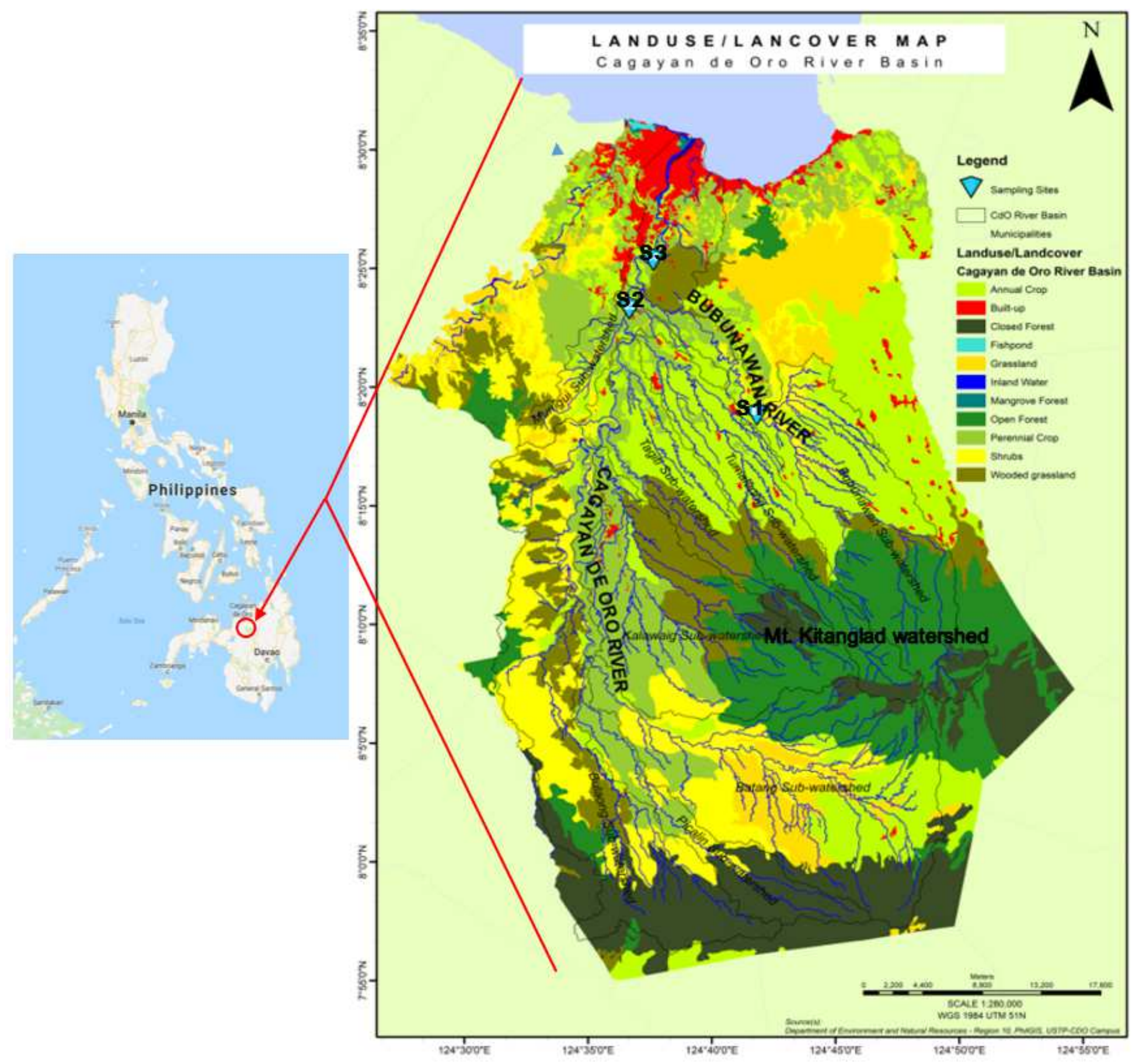

\section{Figure 1}

Sampling sites for the pesticide assessment. These were conducted in the following rivers: S1 Bubunawan River, Libona; S2 Cagayan de Oro River (midstream), Maasin and S3 Cagayan de Oro River (downstream), Taguanaw. Note: The designations employed and the presentation of the material on this map do not imply the expression of any opinion whatsoever on the part of Research Square concerning the legal status of any country, territory, city or area or of its authorities, or concerning the delimitation of its frontiers or boundaries. This map has been provided by the authors. 


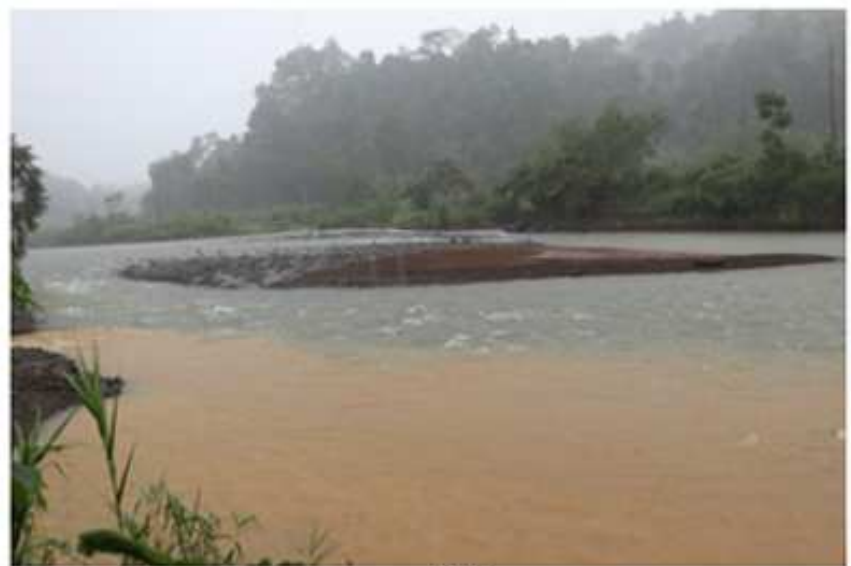

(a1)

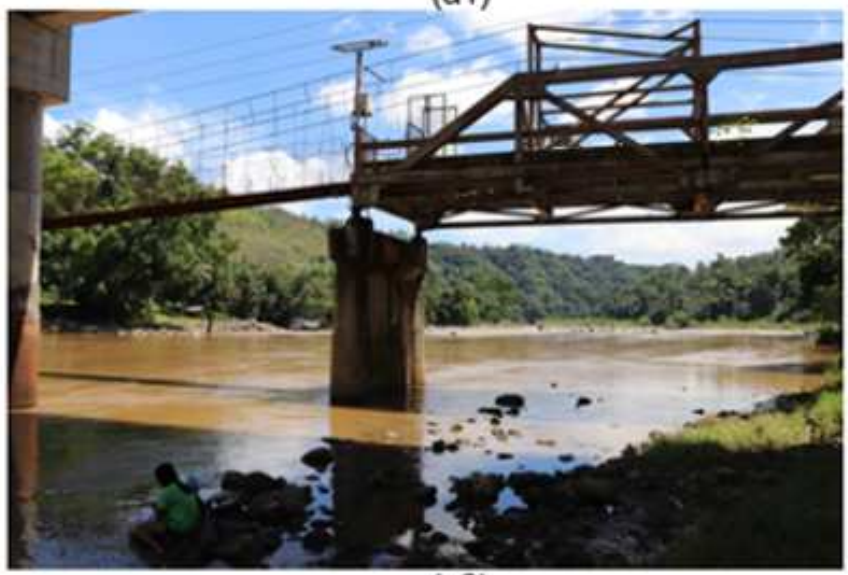

(a2)

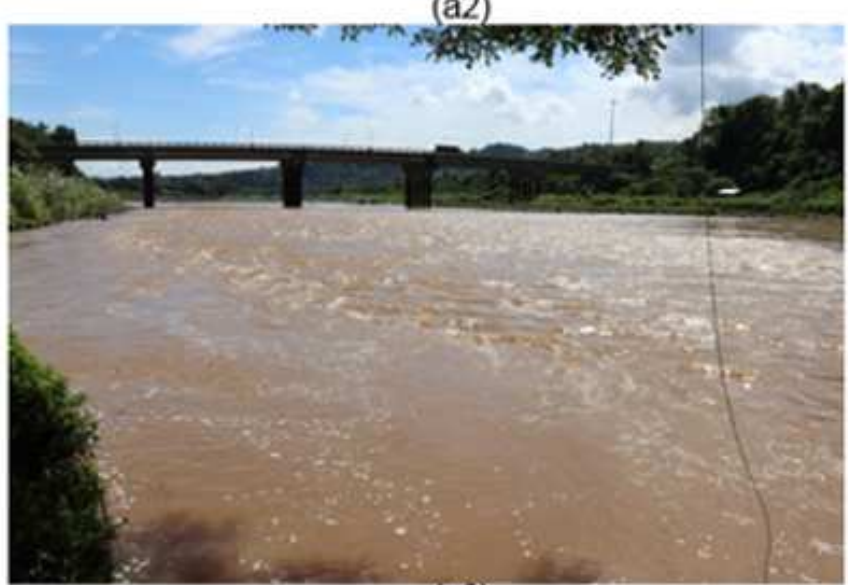

(a3)

(a)

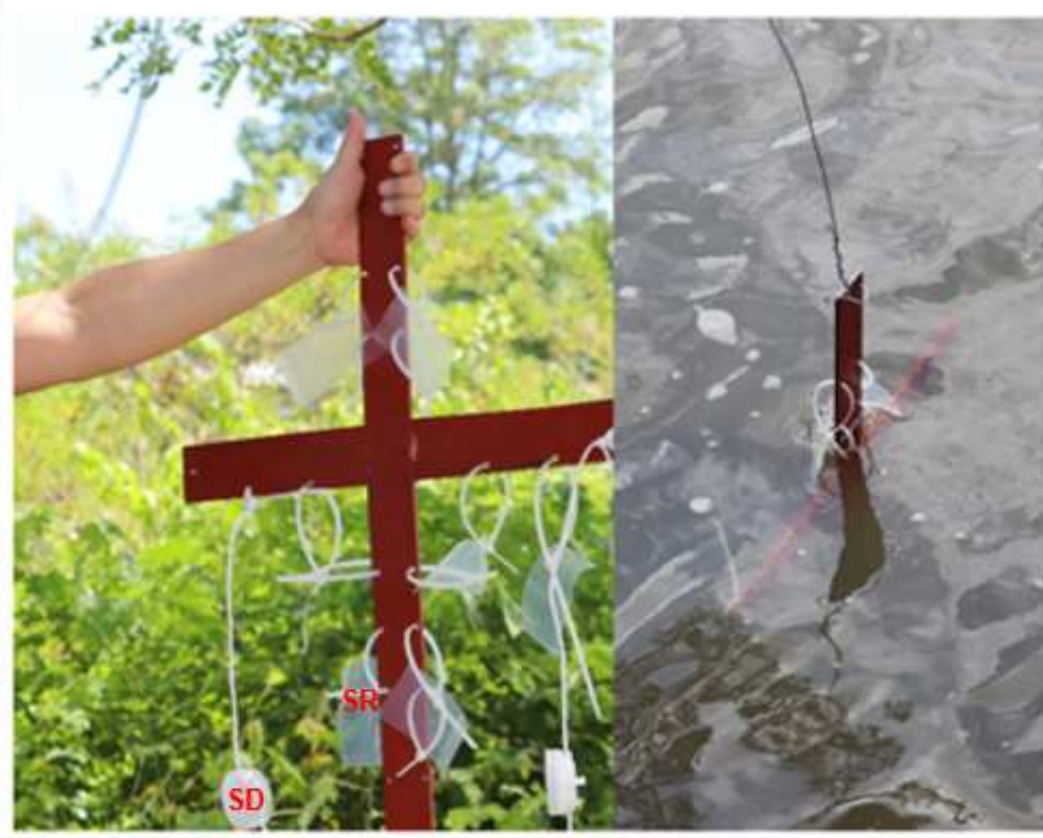

(b1)

(b2)

(b)

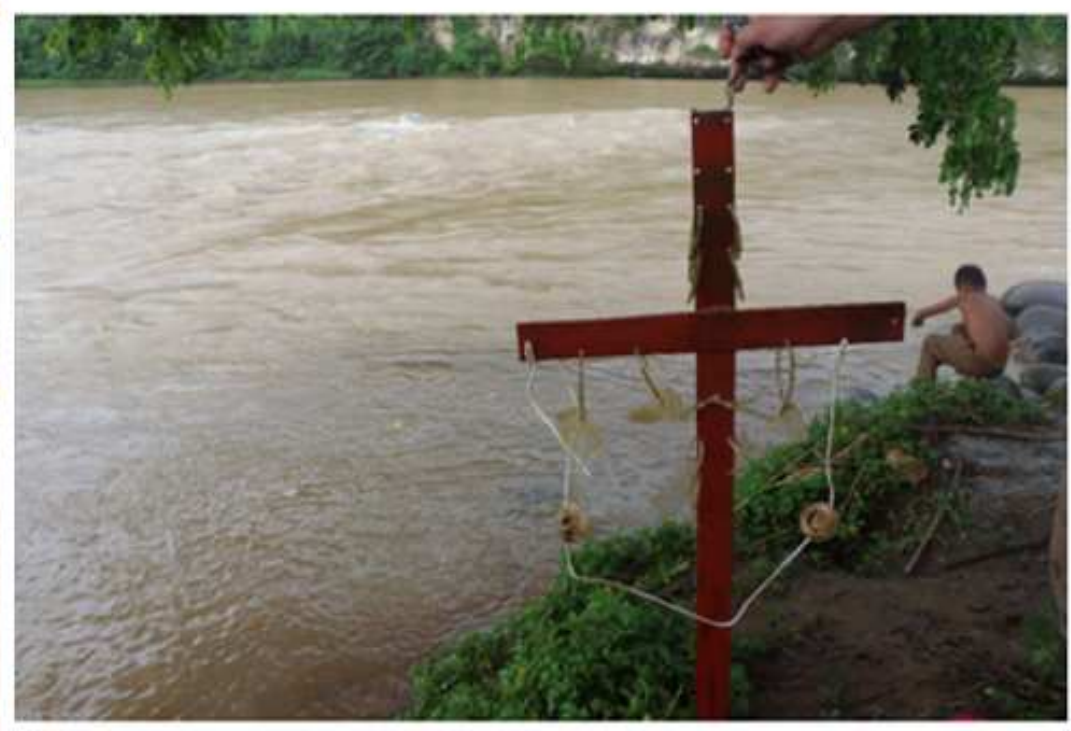

(c)

\section{Figure 2}

Passive samplers' installation, monitoring and dismantling. Passive samplers were installed in three sampling sites (a). The sites were in Bubunawan River, Libona (a1), Cagayan de Oro River, Maasin (a2) and Cagayan de Oro River, Taguanaw (a3). For the installation (b), the samplers (b1) were composed of 6 silicon rubbers (SR) and 3 speedisks (SD) arranged in an iron stand and submerged in river water (b2). After 34 days, the iron stand with the samplers were removed for pesticide analyses (c). 


\section{Fungicides}<smiles>O=C(Nc1ccccc1-c1ccc(Cl)cc1)c1cccnc1Cl</smiles>

Boscalid

2-chloro-N-[2-(4-chlorophenyl)phenyl]pyridine-3carboxamide<smiles>COc1ccc(/C(=C/C(=O)N2CCOCC2)c2ccc(Cl)cc2)cc1OC</smiles>

Z-Dimethomorph

(Z)-3-(4-chlorophenyl)-3-(3,4dimethoxy-phenyl)-1-morpholin-4ylprop-2-en-1-one

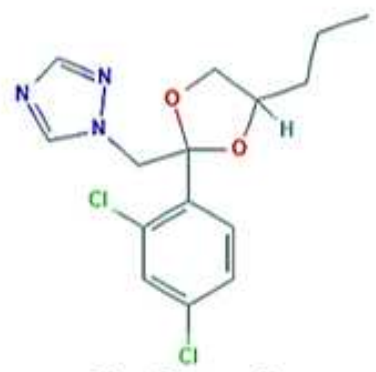

Propiconazole

1-[[2-(2,4-dichlorophenyl)-4-propyl-

1,3-dioxolan-2-yl]methyl]-1,2,4triazole<smiles>COC(=O)Nc1nc2ccccc2[nH]1</smiles>

\section{Carbendazim}

methyl $\mathrm{N}$-(1H-benzimidazol-2-yl) carbamate<smiles>COCC(=O)N(c1c(C)cccc1C)C(C)C(=O)OC</smiles>

Metalaxyl

methyl 2-(N-(2-methoxyacetyl)-2,6dimethylanilino)propanoate<smiles>Cc1cc(C)nc(Nc2ccccc2)n1</smiles>

Pyrimethanil 4,6-dimethyl-N-phenylpyrimidin-2amine

\section{Herbicides}<smiles>CN(C)C(=O)Nc1ccc(Cl)c(Cl)c1</smiles>

Diuron

3-(3,4-Dichlorophenyl)-1,1dimethylurea<smiles>CN(C)C(=O)Nc1ccc(Cl)cc1</smiles>

3-(4-Chlorophenyl)-1,1-dimethylurea<smiles>CCNc1nc(Cl)nc(NCC)n1</smiles>

Simazine

6-chloro-2-N,4-N-diethyl-1,3,5triazine-2,4-diamine

Source: National Center for Biotechnology Informations, PubChem Database.

\section{Figure 3}

Structures of pesticides measured above the applied threshold level of 10ng/L. 


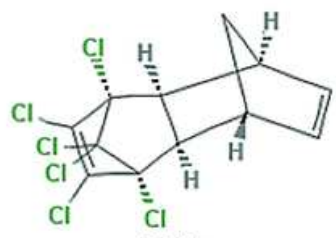

Aldrin

$(1 R, 2 R, 3 R, 6 S, 7 S, 8 S)-1,8,9,10,11,11$ hexachlorotetracyclo[6.2.1.1
4,9 -diene

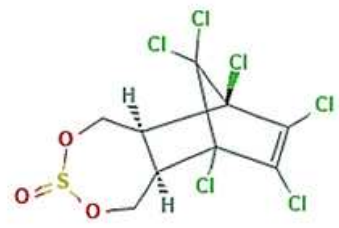

\section{Endosulfan- $\mathrm{a}$}

(2R,8S,9R)-1,9,10,11,12,12-hexachloro-4,6dioxa-5 $\lambda^{4}$-thiatricyclo[7.2.1.0 $\left.0^{2.8}\right]$ dodec-10-ene 5-oxide

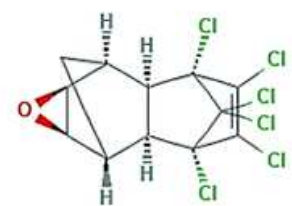

Dieldrin

$(1 R, 2 S, 3 S, 6 R, 7 R, 8 S, 9 S, 11 R)$ $3,4,5,6,13,13$-hexachloro-10oxapentacyclo[6.3.1.1 $\left.1^{3,6} \cdot 0^{2,7} \cdot 0^{9,11}\right]$ tridec- 4 -

ene

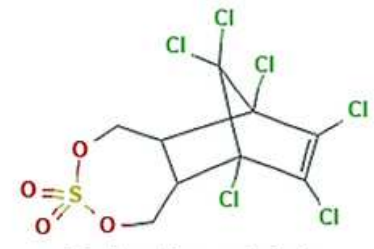

Endosulfan sulphate

1,9,10,11,12,12-hexachloro-4,6-dioxa$5 \lambda^{6}$-thiatricyclo[7.2.1.0.8.8 $]$ dodec-10-ene 5,5-dioxide

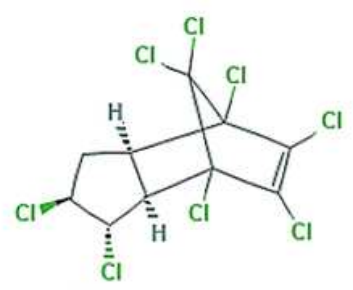

Chlordane-trans (V) $(2 R, 3 S, 4 S, 6 R)-1,3,4,7,8,9,10,10$ octachlorotricyclo[5.2.1.0 $\left.0^{2,6}\right] \mathrm{dec}-8$-ene<smiles>Cl[C@]1[C@@](Cl)[C@@](Cl)[C@](Cl)[C@](Cl)[C@]1Cl</smiles>

HCH- $\alpha$ $\alpha-1,2,3,4,5,6-$ Hexachlorocyclohexane<smiles>ClC1C(Cl)C(Cl)C(Cl)C(Cl)C1Cl</smiles>

HCH-y (lindane) $1,2,3,4,5,6$ hexachlorocyclohexane

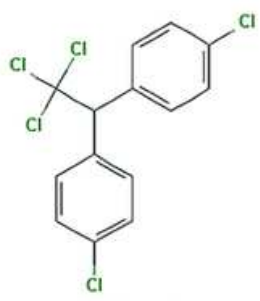

DDT-p, p'

1-chloro-4-[2,2,2-trichloro-1-(4chlorophenyl)ethyl]benzene

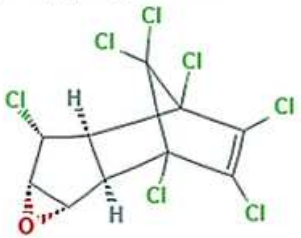

Heptachlor exo-epoxide(B) $(2 R, 3 S, 5 S, 6 R, 7 S)-1,6,8,9,10,11,11$ heptachloro-4-

oxatetracyclo[6.2.1.0 $\left.0^{2,7} \cdot 0^{3.5}\right]$ undec-

Source: National Center for Biotechnology Information, PubChem Database.

\section{Figure 4}

Structures of some organochlorine pesticides measured in traces of $\mathrm{pg}-\mathrm{ng} / \mathrm{L}$

\section{Supplementary Files}

This is a list of supplementary files associated with this preprint. Click to download.

- Tableofcontentsentry.pdf 